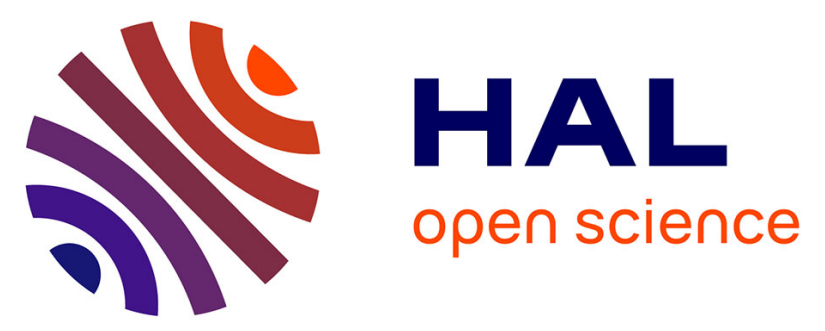

\title{
Bile Acid-Based Drug Delivery Systems for Enhanced Doxorubicin Encapsulation: Comparing Hydrophobic and Ionic Interactions in Drug Loading and Release
}

Alexander J Cunningham, Mattieu Robinson, Xavier Banquy, Jeanne Leblond, X X Zhu

\section{To cite this version:}

Alexander J Cunningham, Mattieu Robinson, Xavier Banquy, Jeanne Leblond, X X Zhu. Bile Acid-Based Drug Delivery Systems for Enhanced Doxorubicin Encapsulation: Comparing Hydrophobic and Ionic Interactions in Drug Loading and Release. Molecular Pharmaceutics, 2018, 10.1021/acs.molpharmaceut.7b01091 . hal-02512388

\section{HAL Id: hal-02512388 \\ https://hal.science/hal-02512388}

Submitted on 23 Mar 2020

HAL is a multi-disciplinary open access archive for the deposit and dissemination of scientific research documents, whether they are published or not. The documents may come from teaching and research institutions in France or abroad, or from public or private research centers.
L'archive ouverte pluridisciplinaire HAL, est destinée au dépôt et à la diffusion de documents scientifiques de niveau recherche, publiés ou non, émanant des établissements d'enseignement et de recherche français ou étrangers, des laboratoires publics ou privés. 


\section{Bile acid-based drug delivery systems for enhanced}

\section{doxorubicin encapsulation: Comparing hydrophobic}

\section{and ionic interactions in drug loading and release}

Alexander J. Cunningham ${ }^{1}$, Mattieu Robinson ${ }^{3}$, Xavier Banquy ${ }^{2}$, Jeanne Leblond-Chain ${ }^{2}$, and

$$
X . X . Z h u^{l, *}
$$

${ }^{1}$ Département de Chimie, Université de Montréal, C.P. 6128, Succ. Centre-ville, Montréal, QC, H3C 3J7, Canada

${ }^{2}$ Faculté de Pharmacie, Université de Montréal, C.P. 6128, Succ. Centre-ville, Montréal, QC, H3C 3J7, Canada

${ }^{3}$ Département de Gérontologie, Université de Sherbrooke, Sherbrooke, QC, J1H 4C4, Canada

*Correspondence to: julian.zhu@umontreal.ca 


\begin{abstract}
Doxorubicin (Dox) is a drug of choice in the design of drug delivery systems directed towards breast cancers, but is often limited by loading and control over its release from polymer micelles. Bile acid-based block copolymers present certain advantages over traditional polymer-based systems for drug delivery purposes, since they can enable a higher drug loading via the formation of a reservoir through their aggregation process. In this study, hydrophobic and electrostatic interactions are compared for their influence on Dox loading inside cholic acid-based block copolymers. Poly(allyl glycidyl ether) (PAGE) and poly(ethylene glycol) (PEG) were grafted from the cholic acid (CA) core yielding a star-shaped block copolymer with 4 arms (CA-(PAGE$b$-PEG) 4 ) and then loaded with Dox via a nanoprecipitation technique. A high Dox loading of 14 $\mathrm{wt} \%$ was achieved via electrostatic as opposed to hydrophobic interactions with or without oleic acid as a cosurfactant. The electrostatic interactions confer a $\mathrm{pH}$ responsiveness to the system. $50 \%$ of the loaded Dox was released at $\mathrm{pH} 5$ in comparison to $12 \%$ at $\mathrm{pH} 7.4$. The nanoparticles with Dox loaded via hydrophobic interactions, did not show such a $\mathrm{pH}$ responsiveness. The systems with Dox loaded via electrostatic interactions showed the lowest $\mathrm{IC}_{50}$ and highest cellular internalization indicating the pre-eminence of this interaction in Dox loading. The blank formulations are biocompatible and did not show cytotoxicity up to $0.17 \mathrm{mg} / \mathrm{mL}$. The new functionalized star block copolymers based on cholic acid show great potential as drug delivery carriers.
\end{abstract}

Keywords: Bile acids, doxorubicin, $\mathrm{pH}$-responsive, drug delivery systems

\title{
INTRODUCTION
}

Breast cancer is the second most prevalent and deadly form of cancer in women. It is currently treated with a combination of surgery and chemotherapy. ${ }^{1}$ Over the course of chemotherapy, not only will the patient suffer greatly from adverse effects, but the cancer often develops resistance 
mechanisms limiting the therapeutic outcome of the treatment. ${ }^{2}$ A common strategy to diminish the side effects inherent to chemotherapy is the encapsulation of the cytotoxic molecules into a drug delivery system. Doxorubicin (Dox) is currently used for breast cancer treatment, but is characterized with severe toxicity due to its off-target effects. Over the past decades, a great deal of research effort has been directed at encapsulating chemotherapeutics in drug delivery systems to increase their safety and transport efficiency to the cancer tissues. Toward this end, polymerbased micelles have attracted much attention with several formulations reaching clinical trials. ${ }^{3,4}$

Polymer-based micelles of a core-shell structure are typically aggregates of polymer chains with a hydrophobic core and hydrophilic corona. They are often the preferred platform for antitumor drug formulations due to their unique core-shell structure, tunable size and shape, ease of synthesis and freedom in design and structure. ${ }^{5,6}$ Much research work has focused on the loading of therapeutically relevant molecules with hydrophobic character inside the core of these micelles. ${ }^{7-10}$ For these systems, the drug loading level is greatly influenced by the hydrophobic interaction of the core-forming block and the drug. ${ }^{11}$ Unfortunately, these formulations are often plagued with a low drug loading and instability in vivo. ${ }^{12-14}$ Strategies to circumvent this limitation include adjustment of the hydrophobic-hydrophilic balance, ${ }^{15-17}$ improvement of the polymer-drug interactions, ${ }^{18-21}$ cross-linking, ${ }^{22-25}$ or conjugation of the drug to the polymer via covalent bonding. ${ }^{15,26-29}$ However, these strategies are often met with challenges, particularly slow, insufficient release. For example, release of a drug conjugated to the polymer necessitates the cleavage of a covalent bond, which may slow down the release. Non-covalent interactions such as ionic interactions and hydrogen bonding may also favour drug loading. ${ }^{30-38}$ Dox bears a positive charge at physiological $\mathrm{pH}$ and is composed of aromatic rings favoring non-covalent interactions via aromatic stacking. Many reports demonstrate the superiority of ionic interactions offering higher drug loading and better stability, and stimuli-sensitive release in response to the environmental $\mathrm{pH}^{30,32-34}$ Despite recent advancements in polymer-based systems, achieving high drug loading and improving tissue biodistribution remain limiting factors. ${ }^{6,15,39}$ In an effort to address the first issue, we intend to study the interaction and forces that govern Dox loading in the context of bile acid-based polymer micelles.

We have previously shown the advantage of using bile acids in the design of drug delivery systems. ${ }^{40-42}$ Micelles formed by bile acid-based polymers are less densely packed than linear 
polymers of similar structure, ${ }^{43}$ creating an internal reservoir that may hold a larger amount of hydrophobic therapeutic molecules. We have studied the loading of hydrophobic itraconazole in bile acid-based nanoparticles. ${ }^{41}$ These formulations reached high loading contents $(35 \mathrm{wt} \%)$ and high encapsulation efficiencies $(>89 \%)$ as well as improved bioavailability and pharmacokinetics of the drug. Dox presents a different challenge with different interaction forces. Therefore, we modified the design of the copolymer based on cholic acid. Hydrophobic poly(allyl glycidyl ether) (PAGE) and hydrophilic poly(ethylene glycol) (PEG) blocks were attached sequentially via anionic polymerization onto a cholic acid (CA) core to yield a starshaped copolymer of 4 arms, CA-(PAGE- $b-\mathrm{PEG})_{4}$ (Scheme 1). The star-shaped polymers based

on bile acids have demonstrated their advantages in biocompatibility and drug loading. ${ }^{44}$ The allyl groups of PAGE can be functionalized post-polymerization. Incorporating $\mathrm{COOH}$ moieties in the polymer backbone can facilitate Dox loading via electrostatic interactions and improve the stability of the complex. The different interactions between Dox and the polymer aggregates (hydrophobic, intrinsic electrostatic, and extrinsic electrostatic) are studied to compare their impact on drug loading, stability, drug release, and in vitro cytotoxicity of the new formulations.

\section{MATERIALS AND METHOD}

\section{Materials}

All chemical reagents were purchased from Sigma-Aldrich and used without further purification unless stated otherwise. For the anionic polymerization, dimethyl sulfoxide (DMSO) and allyl glycidyl ether (AGE) was dried overnight with calcium hydride and distilled immediately prior to use. Ethylene oxide gas was passed through a column of calcium hydride and condensed with dry ice and acetone for quantification before adding to the reaction vessel. Tetrahydrofuran (THF) was dried using sodium under reflux, and methanol was dried using magnesium sulphate. Doxorubicin hydrochloride was purchased from Tecoland.

\section{Synthesis of CA-(PAGE- $b-P E G)_{4}$ via anionic polymerization}

The synthesis and functionalization of the polymers are shown in Scheme 1. For the anionic polymerizations, all glassware was flame-dried under vacuum and purged three times with argon before use. The ethanolamine derivative of cholic acid with four hydroxyl groups was 
synthesized according to a previous method. ${ }^{45,}{ }^{46}$ For anionic polymerization, $5 \beta$-cholanoamide (1.66 mmol, $0.75 \mathrm{~g}$ ) was dissolved in $40 \mathrm{~mL}$ of dry DMSO. A potassium naphthalenide solution in THF was added $(0.44 \mathrm{~mol} / \mathrm{L}, 1.66 \mathrm{mmol}, 1$ eq., $3.74 \mathrm{~mL})$ dropwise using a canula under high pressure. AGE was distilled and added (7.6 g, $66.4 \mathrm{mmol}, 40$ eq.) dropwise using a canula under high pressure. The anionic polymerization was initiated by immersing in an oil bath at $40{ }^{\circ} \mathrm{C}$ and allowed to proceed for $24 \mathrm{~h}$ to allow the consumption of all the AGE monomers. Then, dry ethylene oxide (17 mL, $332.2 \mathrm{mmol}, 200$ eq.) chilled in dry ice/acetone was introduced into the flask and polymerized for another $24 \mathrm{~h}$. The reaction was stopped by quenching the reaction with concentrated hydrochloric acid. The DMSO solution was extracted with hexane $(3 \times 10 \mathrm{~mL})$ to remove the naphthalenide. Distilled water was added to the DMSO solution and the mixture was dialyzed against distilled water ( $48 \mathrm{~h}$ ) through a membrane with 3,500 Da molecular weight cutoff (MWCO) to remove all unreacted monomers. 

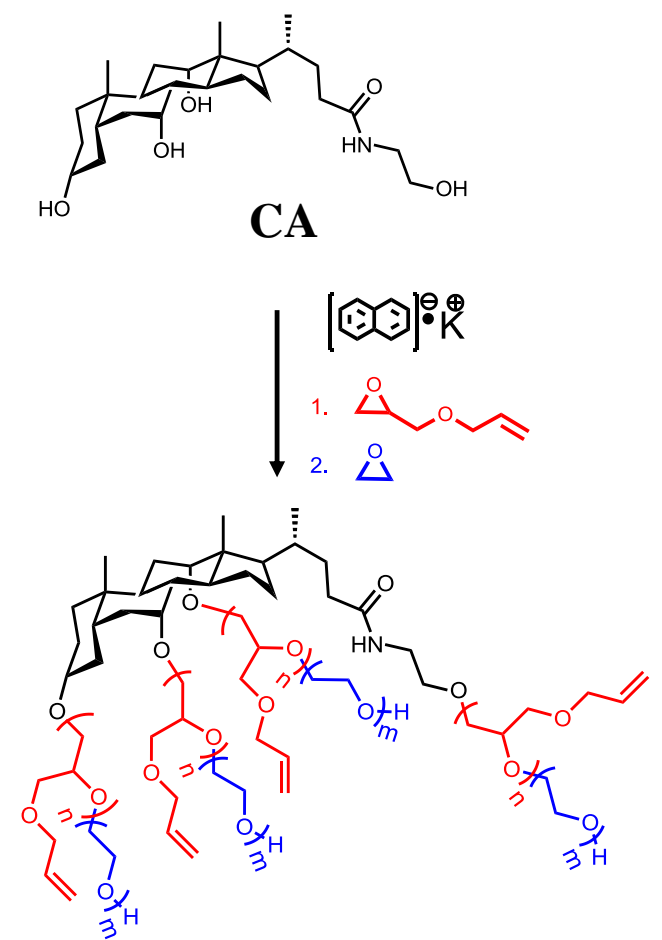

CA-(PAGE) ${ }_{4}$
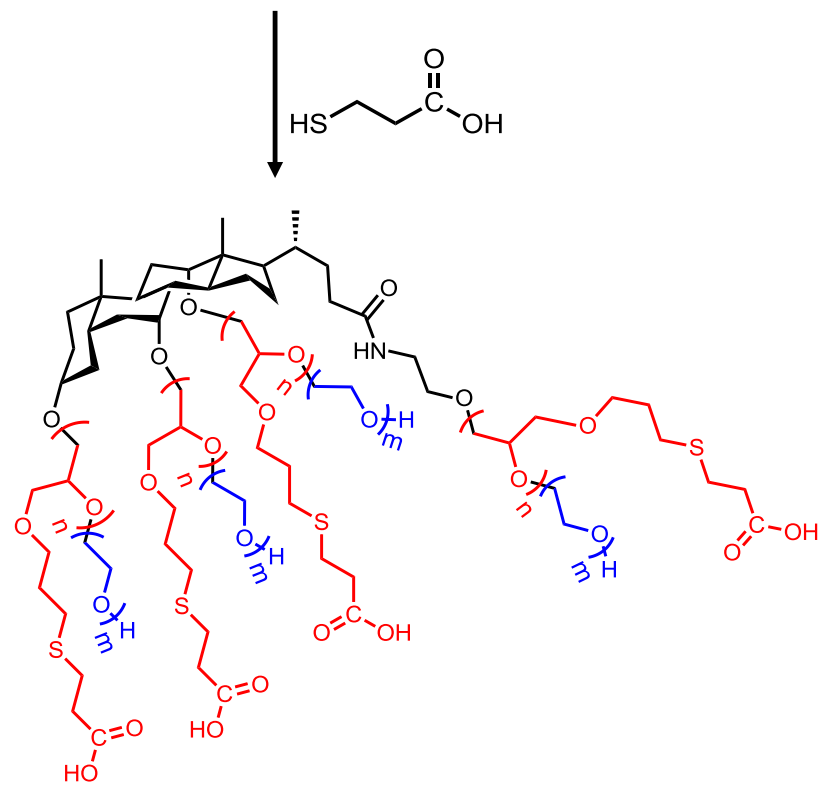

\section{CA-(PAGE-COOH- $b$-PEG $)_{4}$}

Scheme 1. Synthesis of cholic acid-based star polymers via anionic polymerization and the functionalization of the PAGE block through thiol-ene reactions. 


\section{Functionalization of CA-(PAGE- $b$-PEG) $)_{4}$ to CA-(PAGE-COOH- $b$-PEG) $)_{4}$}

The purified and dried CA-(PAGE- $b$-PEG) 4 polymers $(2 \mathrm{~g}, 0.14 \mathrm{mmol})$ were dissolved in dry methanol (20 mL). Azobisisobutyronitrile (0.5 g, $3.2 \mathrm{mmol})$, and 3-mercaptopropionic acid (9.0 g, $84.4 \mathrm{mmol}$ ) were dissolved in the solution which was refluxed at $70{ }^{\circ} \mathrm{C}$ overnight. The reaction was stopped by cooling and methanol was removed. Finally, distilled water was added to dissolve product and remaining reactants and the solution was dialyzed against distilled water for $48 \mathrm{~h}$ and dried to yield CA-(PAGE-COOH- $b-\mathrm{PEG})_{4}$.

\section{Characterization methods}

The molar mass of the polymers was determined by size exclusion chromatography (SEC) on a Breeze system from Waters equipped with a 717 plus autosampler, a 1525 Binary HPLC pump, and a 2410 refractive index detector and three consecutive styragel columns with a flow rate of $1.0 \mathrm{~mL} / \mathrm{min}$. Polystyrene standards were used for calibration. All samples were filtered on a PTFE $0.2 \mu \mathrm{m}$ filters prior to injection. ${ }^{1} \mathrm{H}-\mathrm{NMR}$ spectra were recorded on a Bruker AV400 spectrometer operating at $400 \mathrm{MHz}$. Dynamic light scattering (DLS) measurements were performed on a Malvern Zetasizer NanoZS instrument equipped with a $\mathrm{He}-\mathrm{Ne}$ laser with a wavelength of $633 \mathrm{~nm}$, and at a scattering angle of $173.5^{\circ}$. Intensity-averaged hydrodynamic diameters of the dispersions were obtained using the non-negative least-squares algorithm (NNLS). Disposable cuvettes were used, and the samples were filtered using $0.45 \mu \mathrm{m}$ Nylon filters prior to measurements. Sample concentration used was $1 \mathrm{mg} / \mathrm{mL}$ for both blank and loaded micelles. Dox concentration was determined by recording the fluorescence spectra on a Cary eclipse fluorescence spectrophotometer with excitation and emission wavelengths of 485 and $590 \mathrm{~nm}$, respectively, and a bandwidth of $5 \mathrm{~nm}$. The transmission electron microscope (TEM) images were obtained on a FEI Tecnai 12 at $80 \mathrm{kV}$ and equipped with an AMT XR80C CCD camera system. TEM samples were prepared by drop-casting blank micelles on a carboncoated copper grid (300 mesh, Carbon Type-B, Ted Pella Inc.).

\section{Doxorubicin loading and release}

Dox was encapsulated into the micelles by a nanoprecipitation method. Briefly, for the CA(PAGE-COOH- $b$-PEG) $)_{4}$ sample, the copolymers $(10 \mathrm{mg})$ were dissolved in methanol $(1 \mathrm{~mL})$ 
along with Dox (2 mg) with gentle stirring. The solution was added dropwise into $10 \mathrm{~mL}$ PBS buffer ( $\mathrm{pH} 7.4,10 \mathrm{mM}$ ) over a period of 10 min using a syringe pump. The resulting PBS solution was stirred gently for $10 \mathrm{~min}$ before purification via dialysis (MWCO 6,000-8,000 Da) against $1 \mathrm{~L}$ PBS (pH 7.4, $10 \mathrm{mM}$ ) for $24 \mathrm{~h}$, changing the outer media twice. Samples of the outer media were taken before replenishment to quantify the amount of Dox released. The same procedure was repeated for the CA-(PAGE- $b-\mathrm{PEG})_{4}+\mathrm{OA}$ sample, with a slight modification by using $10 \mathrm{mg}$ of copolymer and $0.126 \mathrm{mg}$ of OA. For the CA-(PAGE- $b$-PEG) $)_{4}$ system, the same procedure was followed by using $10 \mathrm{mg}$ of CA-(PAGE- $b$-PEG) $)_{4}$ alone and Dox which was reacted overnight with 1.5 eq TEA prior to the nanoprecipitation. Dox loading was measured by quantifying the amount of Dox released during the purification and subtracting this value from the amount of Dox in the feed. The quantification was achieved by taking $1 \mathrm{~mL}$ of the outer water, mixing with $1 \mathrm{~mL}$ DMSO, measuring the fluorescence intensity on a Cary fluorescence spectrometer (excitation $485 \mathrm{~nm}$, emission $590 \mathrm{~nm}$ ), and comparing with a calibration curve for Dox in DMSO/PBS (1:1 Vol.).

$$
\begin{gathered}
D L C(w t \%)=\frac{\text { weight of loaded drug }}{\text { weight of copolymer }} \times 100 \% \\
E E(\%)=\frac{\text { weight of loaded drug }}{\text { weight of drug in feed }} \times 100 \%
\end{gathered}
$$

The Dox release from the different formulations was determined with a dialysis method at different $\mathrm{pH}$. Briefly, $2 \mathrm{~mL}$ of the drug-loaded formulations were placed in a dialysis bag (MWCO 6,000-8,000 Da) and dialyzed against $225 \mathrm{~mL}$ of the appropriate buffer at $37{ }^{\circ} \mathrm{C}$; PBS $\mathrm{pH} 7.4$ or acetate buffer $\mathrm{pH} 510 \mathrm{mM}$ for the experiments conducted at $\mathrm{pH} 7.4$ and 5 , respectively. $1 \mathrm{~mL}$ of the outer media was taken at regular intervals and replenished with fresh buffer. The amount of Dox released was quantified by fluorescence spectroscopy with the appropriate calibration curve. All experiments were conducted in triplicates and the results are presented as average values.

\section{In vitro cytotoxicity assay}

HeLa cells were grown in Dulbecco's Modified Eagle's Medium (DMEM) medium supplemented with $10 \%$ Fetal Bovine Serum (FBS). MTT assay was used to determine the 
cytotoxicity of the blank formulations and the $\mathrm{IC}_{50}$ for free Dox and all three Dox-loaded formulations. MTT assay was conducted according to manufacturer's protocol. HeLa cells were plated on a 96-well plate at a seeding density of 5,000 cells per well in $200 \mu \mathrm{L}$ DMEM and allowed to adhere overnight $\left(37^{\circ} \mathrm{C}, 5 \% \mathrm{CO}_{2}, 12 \mathrm{~h}\right) .40 \mu \mathrm{L}$ of the formulation to be tested was added to each well. The plates were incubated for $48 \mathrm{~h}\left(37^{\circ} \mathrm{C}, 5 \% \mathrm{CO}_{2}\right)$. Medium was removed and replaced with $100 \mu \mathrm{L}$ of fresh medium. $10 \mu \mathrm{L}$ of MTT solution $(5 \mathrm{mg} / \mathrm{mL})$ was added to each well and incubated $\left(37^{\circ} \mathrm{C}, 5 \% \mathrm{CO}_{2}\right)$ for $4 \mathrm{~h}$. DMEM medium was carefully removed from each well and replaced with DMSO. MTT crystals were dissolved and the absorbance was read at $590 \mathrm{~nm}$ using a plate reader. Cytotoxicity is reported as compared to absorbance measured for control (untreated cells). To calculate the $\mathrm{IC}_{50}$, a linear regression was intrapolated by drawing a straight line through the inflection in the viability curve. The $\mathrm{IC}_{50}$ value was obtained by setting $\mathrm{y}=50 \%$ from the linear equation obtained and solving for $\mathrm{x}$.

\section{Fluorescence activated cell sorting (FACS) assay}

HeLa cells were grown in DMEM medium supplemented with 10\% FBS. Cells were seeded in a 24-well plate at a seeding density of $5 \times 10^{4}$ cells/well and allowed to adhere overnight $\left(37^{\circ} \mathrm{C}\right.$, $5 \% \mathrm{CO}_{2}$ ). The cells were washed with PBS and replenished with fresh medium. Free Dox and Dox-loaded formulations were added to the cells to yield a final concentration of 1 and $10 \mu \mathrm{M}$ Dox in $550 \mu \mathrm{L}$ DMEM. After $1 \mathrm{~h}$ incubation, the cells were washed with PBS, trypsinized (100 $\mu \mathrm{L}$ of $0.25 \%$ Trypsin/EDTA), and suspended in FACS buffer (400 $\mu \mathrm{L}, 95 \%$ PBS, $5 \%$ FBS, 1 mM EDTA). The cells were observed on a FACScalibur flow cytometer (BD Biosciences, San Jose, CA, USA). Dox concentration internalized in the cells was calculated with respect to control samples (untreated cells). The experiment was done in triplicates.

\section{RESULTS AND DISCUSSION}

\section{Drug formulation}

To study the interactions driving the Dox loading, three formulations were prepared (Figure 1). The first is composed of CA-(PAGE- $b-\mathrm{PEG})_{4}$ alone, in which only hydrophobic interactions are present to ensure Dox loading inside the core of the micelles. The hydrophobicity is conferred from the hydrophobic face of the cholic acid and the hydrophobic PAGE block, while the 
hydrophilic PEG block promotes micelle formation and stability in the aqueous environment. The second formulation is composed of functionalized PAGE blocks bearing carboxylic acid groups (CA-(PAGE-COOH- $b$-PEG) $)_{4}$ ). Here, electrostatic interactions between the $\mathrm{NH}_{2}$ groups of Dox and the $\mathrm{COOH}$ groups attached on PAGE drives the loading of Dox into the middle block in addition to the hydrophobic core. In this situation, the electrostatic interactions may be tuned by varying the PAGE block length. The third formulation is composed of CA-(PAGE- $b$-PEG) 4 supplemented with oleic acid (OA). OA is used to mimic the carboxylic acid content on the CA(PAGE-COOH- $b$-PEG) $)_{4}$ formulation. The carboxylic acid groups of OA can complex electrostatically to Dox and the aliphatic chain of OA imparts an enhanced hydrophobicity thereby increasing Dox loading while reducing its premature release at physiological $\mathrm{pH} .{ }^{47}$ Here the electrostatic interactions are extrinsic to the system; the $\mathrm{COOH}$ group of $\mathrm{OA}$ and the increased hydrophobicity imparted by OA drive the loading of Dox inside the nanoparticles.

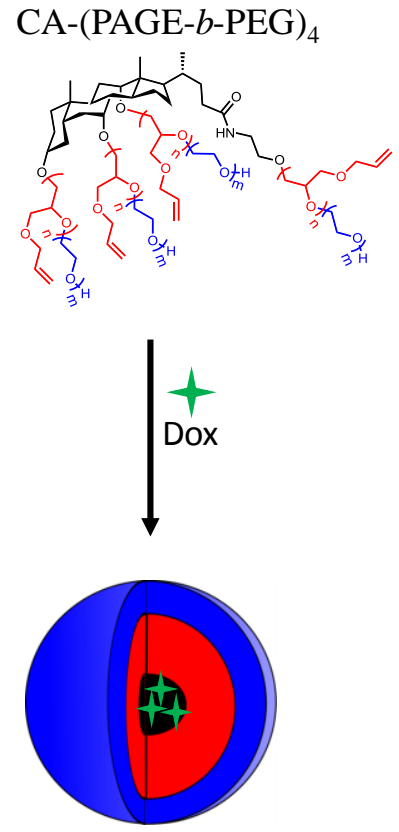

Hydrophobic interactions

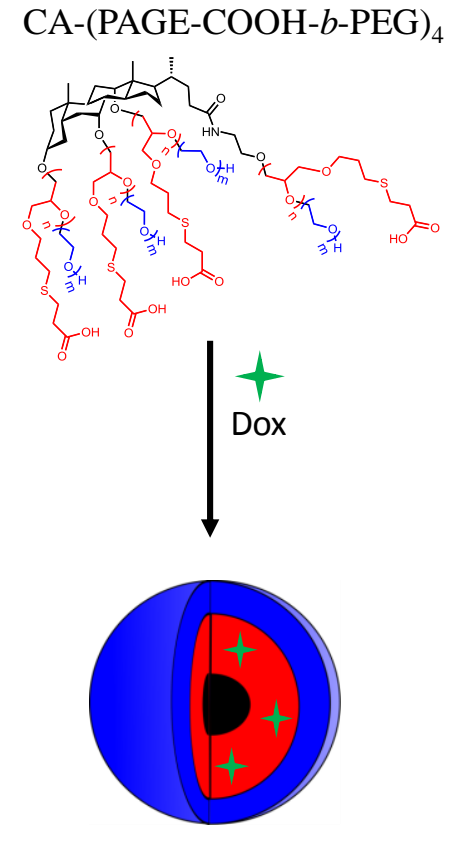

Intrinsic electrostatic interactions

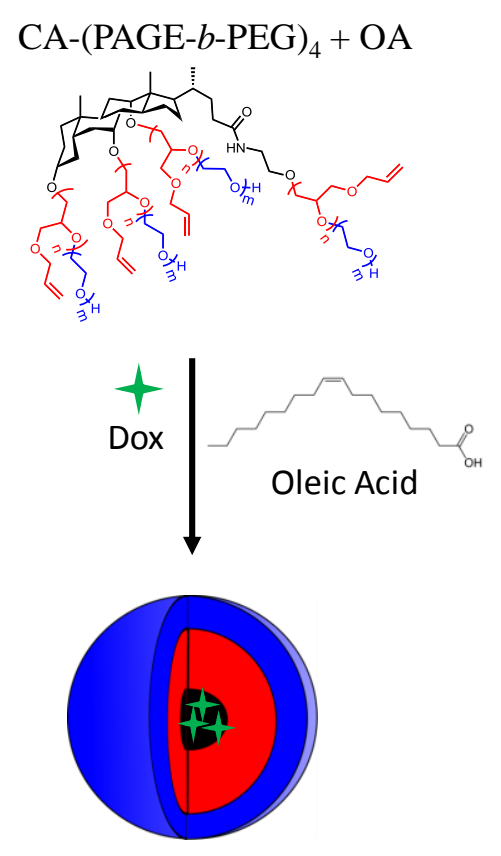

Extrinsic electrostatic interactions

Figure 1. Formulations based on different drug-polymer interactions. For CA-(PAGE- $b$-PEG) 4 , Dox is loaded via hydrophobic interactions between the drug and the core of the micelle 
composed of cholic acid and hydrophobic PAGE. For CA-(PAGE-COOH- $b-\mathrm{PEG})_{4}$, Dox is loaded via intrinsic electrostatic interactions between the drug and the pendant $\mathrm{COOH}$ groups. For CA-(PAGE- $b-\mathrm{PEG})_{4}+\mathrm{OA}$, the electrostatic interactions are perceived as extrinsic because they appear on OA only. The hydrophobicity of the OA aliphatic chains may drive the loading of Dox more toward the hydrophobic core.

\section{Polymer synthesis and characterization}

The star-shaped block copolymers were synthesized as shown in Scheme 1. An ethanolamine derivative of CA with four hydroxyl groups was used as initiator for the anionic polymerization of allyl glycidyl ether (AGE), followed by the addition of ethylene glycol (EG) to afford a starshaped CA-(PAGE- $b$-PEG) 4 with 4-arms composed of hydrophobic PAGE and hydrophilic PEG blocks. The copolymer obtained was analyzed by SEC and ${ }^{1} \mathrm{H}-\mathrm{NMR}$ (Figures S1 and S2). The SEC traces show monomodal, narrow distributions and an increase in $\mathrm{M}_{\mathrm{n}}$ when going from CA$(\mathrm{PAGE})_{4}$ to CA-(PAGE- $b$-PEG) $)_{4}$. The NMR signals at $0.58,0.81$, and $0.92 \mathrm{ppm}$ were assigned to the $18-\mathrm{CH}_{3}, 19-\mathrm{CH}_{3}$, and $21-\mathrm{CH}_{3}$ groups, respectively, on the cholic acid backbone. These peaks were used as reference for the analysis of the peaks at 5.79-5.92 and 3.35-3.60 ppm, which correspond respectively to the $\mathrm{CH}_{2}$ protons on the PAGE block and on both PAGE and PEG. The block copolymer was determined to be $\mathrm{CA}-\left(\mathrm{AGE}_{19}-b-\mathrm{EG}_{30}\right)_{4}$ with 19 monomer units of AGE and 30 monomer units of EG (Table 1). The presence of four arms was confirmed by reacting the polymers with trifluoroacetic anhydride and by the appearance of the methylene protons at $4.5 \mathrm{ppm}$, corresponding to protons of the PEG terminal $\mathrm{CH}_{2}$ unit coupled with the trifluoroacetic group. Then, the allyl side chains from the PAGE block were functionalized with mercaptopropionic acid with close to $100 \%$ functionalization as confirmed by ${ }^{1} \mathrm{H}-\mathrm{NMR}$ (Figure S2).

Table 1. SEC and ${ }^{1} \mathrm{H}-\mathrm{NMR}$ results for the anionic polymerization of CA with AGE and EG monomers.

\begin{tabular}{|c|c|c|c|}
\hline \multirow[b]{2}{*}{ Polymer } & \multicolumn{2}{|c|}{ Molecular Weight $\left(M_{n}, g / m o l\right)$} & \multirow[b]{2}{*}{$\mathrm{D}$} \\
\hline & ${ }^{1} \mathrm{H}-\mathrm{NMR}$ & SEC & \\
\hline CA- $\left(\mathrm{PAGE}_{19}\right)_{4}$ & 9,100 & 3,900 & 1.10 \\
\hline $\mathrm{CA}-\left(\mathrm{PAGE}_{19}-b-\mathrm{PEG}_{30}\right)_{4}$ & 14,400 & 8,400 & 1.13 \\
\hline
\end{tabular}


The critical micellar concentration (CMC) of the bile acid derivative in water was measured with fluorescence spectroscopy using pyrene as a probe. ${ }^{48}$ Pyrene fluorescence is measured with increasing concentration of the block copolymers and the CMC is calculated from a plot of the excitation intensity ratio $\mathrm{I}_{383} / \mathrm{I}_{373}$ as a function of polymer concentration. The CMC for CA(PAGE-b-PEG) 4 is determined to be $20 \mu \mathrm{g} / \mathrm{mL}$ (Figure S3), comparable to typical polymer-based micellar systems found in the literature. ${ }^{43,49-51}$

Particle size and distribution were analyzed with dynamic light scattering (DLS) and transmission electron microscopy (TEM), before and after Dox loading. The DLS results show that CA-(PAGE- $b$-PEG) $)_{4}$ forms larger aggregates $(\mathrm{d}=62 \pm 18 \mathrm{~nm})$ than (CA-(PAGE- $b$-PEG) ${ }_{4}$ with OA, and CA-(PAGE-COOH- $b$-PEG) $)_{4}$ ) (Figure 2). CA-(PAGE- $\left.b-\mathrm{PEG}\right)_{4}$ mixed with OA, a surfactant, forms mixed micelles smaller in diameter $(27 \pm 10 \mathrm{~nm})$. The negatively charged $\mathrm{COOH}$ moieties may induce an electrostatic repulsion between individual polymer chains leading to smaller micelles. These results are corroborated with the TEM images showing spherical aggregates with a dense core (Figure 3). 


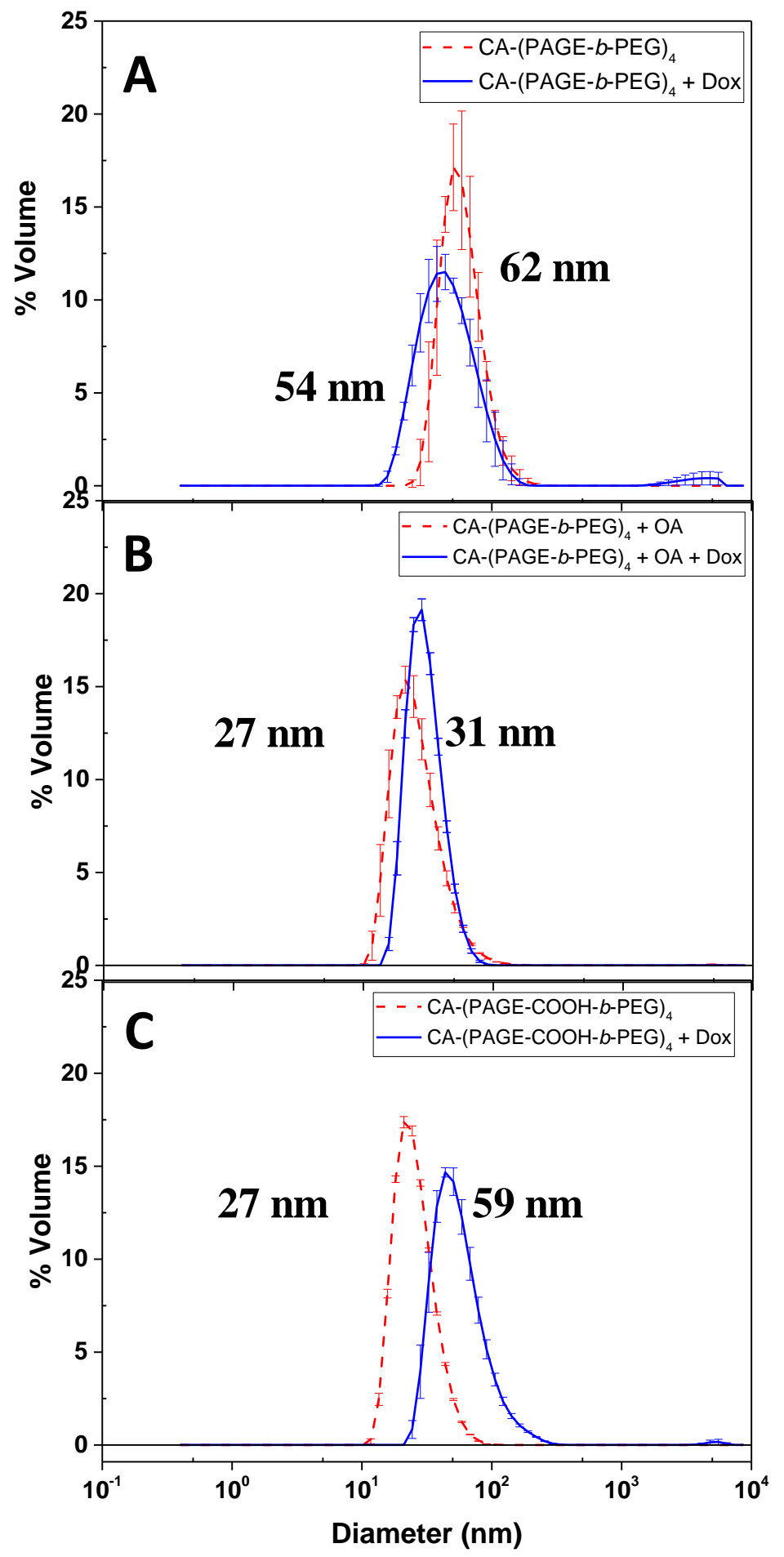

Figure 2. The volume-size distribution of (A) CA-(PAGE- $b-\mathrm{PEG})_{4}$ with and without Dox, (B) CA-(PAGE- $b-\mathrm{PEG})_{4}+\mathrm{OA}$ with and without Dox, and (C) CA-(PAGE-COOH- $\left.b-\mathrm{PEG}\right)_{4}$ with and without Dox as determined by DLS. Blank micelles and formulations are obtained at $1 \mathrm{mg} / \mathrm{mL}$ and filtered with $0.45 \mu \mathrm{m}$ PES filters prior to DLS measurements. 
Table 2 shows the zeta potentials measured for the nanoparticles. The CA-(PAGE- $b$-PEG) 4 micelles have a zeta potential close to neutral with a value of $-3.9 \pm 0.4 \mathrm{mV}$, whereas the presence of the negatively charged $\mathrm{COOH}$ moieties lead to larger negative values, $-9.2 \pm 0.7 \mathrm{mV}$ for CA-(PAGE- $b$-PEG) $)_{4}$ with OA and $-17.2 \pm 0.1 \mathrm{mV}$ for the CA-(PAGE-COOH- $\left.b-\mathrm{PEG}\right)_{4}$ micelles where the $\mathrm{COOH}$ groups in the middle block are more exposed to the surface.

Table 2. Aggregate size and Dox-loading of the formulations based on star-shaped block copolymers.

\begin{tabular}{|c|c|c|c|c|c|c|}
\hline \multirow[t]{2}{*}{ Drug formulation } & \multicolumn{2}{|c|}{$\begin{array}{l}\text { Diameter blank micelle } \\
\text { and Dox-loaded micelle } \\
\qquad(\mathrm{nm})\end{array}$} & \multirow[t]{2}{*}{$\begin{array}{l}\text { Micelle } \\
\text { dispersity } \\
\text { from DLS }\end{array}$} & \multirow[t]{2}{*}{$\begin{array}{l}\text { Zeta potential } \\
(\mathrm{mV})\end{array}$} & \multirow[t]{2}{*}{$\operatorname{DLC}(w t \%)^{\ddagger}$} & \multirow[t]{2}{*}{$\mathrm{EE}(\%)^{\dagger}$} \\
\hline & DLS & TEM & & & & \\
\hline CA-(PAGE- $b$-PEG) $)_{4}$ & $62 \pm 18$ & $57 \pm 29$ & 0.2 & $-3.9 \pm 0.4$ & \multirow{2}{*}{10} & \multirow{2}{*}{50} \\
\hline CA-(PAGE- $b-\mathrm{PEG})_{4}+$ Dox & $54 \pm 27$ & $29 \pm 7$ & 0.2 & $-0.29 \pm 0.06$ & & \\
\hline CA-(PAGE- $b-\mathrm{PEG})_{4}+\mathrm{OA}$ & $27 \pm 14$ & $26 \pm 7$ & 0.1 & $-9.2 \pm 0.7$ & \multirow{2}{*}{11.6} & \multirow{2}{*}{58} \\
\hline CA-(PAGE-b-PEG)4 + OA + Dox & $31 \pm 10$ & $34 \pm 14$ & 0.3 & $-5.4 \pm 0.2$ & & \\
\hline CA-(PAGE-COOH- $b-\mathrm{PEG})_{4}$ & $27 \pm 10$ & $28 \pm 11$ & 0.2 & $-17.2 \pm 0.09$ & \multirow{2}{*}{14} & \multirow{2}{*}{72} \\
\hline CA-(PAGE-COOH- $b$-PEG $)_{4}+$ Dox & $59 \pm 32$ & $40 \pm 11$ & 0.1 & $-17.4 \pm 0.9$ & & \\
\hline
\end{tabular}

* All samples were examined at a $1 \mathrm{mg} / \mathrm{mL}$ concentration in $10 \mathrm{mM}$ PBS at $7.4 \mathrm{pH}$ with $154 \mathrm{mM}$ $\mathrm{NaCl}$.

${ }^{\ddagger}$ Drug loading content.

${ }^{\dagger}$ Encapsulation efficiency.

\section{Doxorubicin loading and release}

We hypothesize that electrostatic interactions enhance the loading of Dox in comparison to Dox via hydrophobic interaction. To study these interaction forces, the three different formulations were loaded with equal amount of Dox using the same loading procedure. The encapsulation efficiencies and drug loading contents are listed in Table 1. The CA-(PAGE- $b$ PEG) $)_{4}$ aggregates showed drug loading content of $10 \mathrm{wt} \%$ and an encapsulation efficiency of $50 \%$. Adding OA to the formulation enabled a higher drug loading and encapsulation efficiency, $11.6 \mathrm{wt} \%$ and $58 \%$, respectively, most likely due to an increased hydrophobicity of the Dox complex. ${ }^{47}$ Functionalizing the bile acid-based polymers with pendant $\mathrm{COOH}$ moieties resulted in an improvement of the drug loading to $14 \mathrm{wt} \%$ and loading efficiency to $72 \%$. 
In the case of CA-(PAGE- $b-\mathrm{PEG})_{4}$ and CA-(PAGE- $\left.b-\mathrm{PEG}\right)_{4}$ with OA, there is a small size increase upon Dox loading (Figure 2). TEM images in Figure 3 show that upon Dox loading, both CA-(PAGE- $b-\mathrm{PEG})_{4}$ and CA-(PAGE- $\left.b-\mathrm{PEG}\right)_{4}$ with OA retain their spherical shape. In contrast, the Dox-loaded CA-(PAGE-COOH- $b-\mathrm{PEG})_{4}$ micelles showed the formation of aggregates larger in size (Figure 2) and the spherical micelles changed to vesicular-shaped polymersomes (Figure 3). Zeta potential measurements showed a slight increase in the surface charge of the micelles upon Dox loading when compared to the blank micelles (Table 1) due to the presence of positively charged Dox loaded in the reservoir of the polymersome and adsorbed on the surface of the micelles.

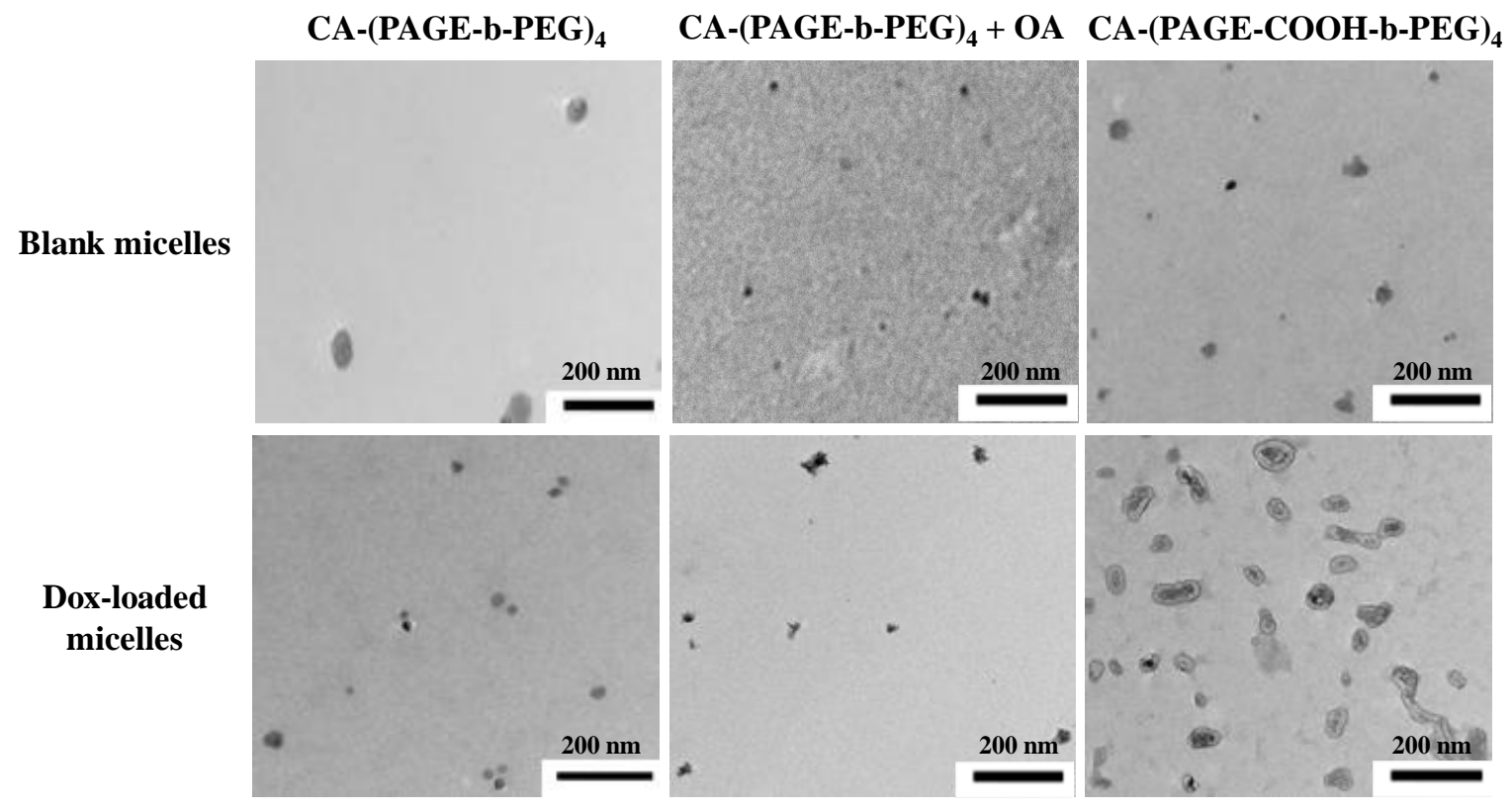

Figure 3. Transmission electron micrograph images of the micelles formed: (top) blank formulations and (bottom) Dox-loaded formulations ( $1 \mathrm{mg} / \mathrm{mL}$ samples).

In vitro Dox release profiles at $37^{\circ} \mathrm{C}$ were obtained at two different $\mathrm{pH}$ values, mimicking the endosomal $\mathrm{pH}$ at 5 encountered by the nanoparticles upon cellular entry and the physiological $\mathrm{pH}$ at 7.4 sensed by the nanoparticles during transport. The objective of this experiment is to compare the release kinetics of the different formulations to assess the impact of the interaction forces on the release profile. Moreover, the presence of the COOH moieties in the CA-(PAGE$\mathrm{COOH}-b$-PEG) $)_{4}$ formulation bestows $\mathrm{pH}$-responsiveness to the system, an advantage compared to hydrophobic entrapment alone. The results shown in Figure 4 compare the Dox release 
profiles at both $\mathrm{pH}$ values for all three formulations. As a control, free Dox was loaded in the dialysis bag and its release was monitored over time. The declivity observed for free Dox at $\mathrm{pH}$ 7.4 can be explained by the possible degradation of the drug as reported previously. ${ }^{52,53}$ At pH 5 the free Dox is more stable. ${ }^{54}$ The degradation of Dox was also observed for the CA-(PAGE- $b$ $\mathrm{PEG})_{4}$ with $\mathrm{OA}$ formulation at $\mathrm{pH} 7.4$, but not for the other two formulations for which the quantity of Dox released was small so that the degradation was not measured at an appreciable amount.

All formulations show a biphasic release with an initial burst release within the first $8 \mathrm{~h}$, followed by a slower, continuous release. The CA-(PAGE- $b$-PEG) $)_{4}$ formulation should be $\mathrm{pH}-$ irresponsive but shows an increase in the release from 7.2 to $23 \%$ when the $\mathrm{pH}$ changes from 7.4 to 5 . The higher solubility of Dox at pH 5 facilitates its release. ${ }^{55}$ For the CA-(PAGE- $b$-PEG) 4 with OA formulation, the release increased from 24 to $35 \%$ when $\mathrm{pH}$ varies from 7.4 to 5 (Table 3). In this case, Dox interacts electrostatically with the negative $\mathrm{COOH}$ moieties on the OA and the long aliphatic chain of OA provides a higher hydrophobicity for Dox to remain in the core. ${ }^{47}$ At $\mathrm{pH} 5$, the $\mathrm{COOH}$ groups are partially protonated weakening their electrostatic interaction with Dox, while the core remains hydrophobic and keeps the drug inside. Therefore, lowering the $\mathrm{pH}$ does not significantly impact the release of Dox from the core of the micelle. ${ }^{56}$ Finally, the CA(PAGE-COOH- $b$-PEG) $)_{4}$ formulation shows the highest difference between the two $\mathrm{pHs}$, with a change in release from 16 to $51 \%$ when the $\mathrm{pH}$ changed from 7.4 to 5 . This demonstrates the $\mathrm{pH}$ responsiveness of the formulation. The $\mathrm{COOH}$ groups on the polymer protonate at $\mathrm{pH} 5$, thereby disrupting the electrostatic interaction between the polymer and the drug helping with its release. Moreover, this formulation shows a more stable drug loading at physiological $\mathrm{pH}$ than the other two formulations.

Table 3. The maximum amount of Dox released in response to $\mathrm{pH}$ change.

\begin{tabular}{|c|c|c|}
\hline \multirow[b]{2}{*}{ Drug formulation } & \multicolumn{2}{|c|}{ Dox release } \\
\hline & $\mathrm{pH} 7.4^{1}$ & $\mathrm{pH} 5^{2}$ \\
\hline CA-(PAGE- $b$-PEG) $)_{4}$ & 7.2 & 23.0 \\
\hline $\mathrm{CA}-(\mathrm{PAGE}-b-\mathrm{PEG})_{4}+\mathrm{OA}$ & 24.2 & 35.3 \\
\hline CA-(PAGE-COOH- $b$-PEG $)_{4}$ & 16.3 & 51.5 \\
\hline
\end{tabular}


${ }^{1}$ Maximum Dox released at $\mathrm{pH} 7.4$ and ${ }^{2}$ maximum Dox released at $\mathrm{pH}$, the values at $48 \mathrm{~h}$ were used. This value gives a measure of the $\mathrm{pH}$ responsiveness of the system.

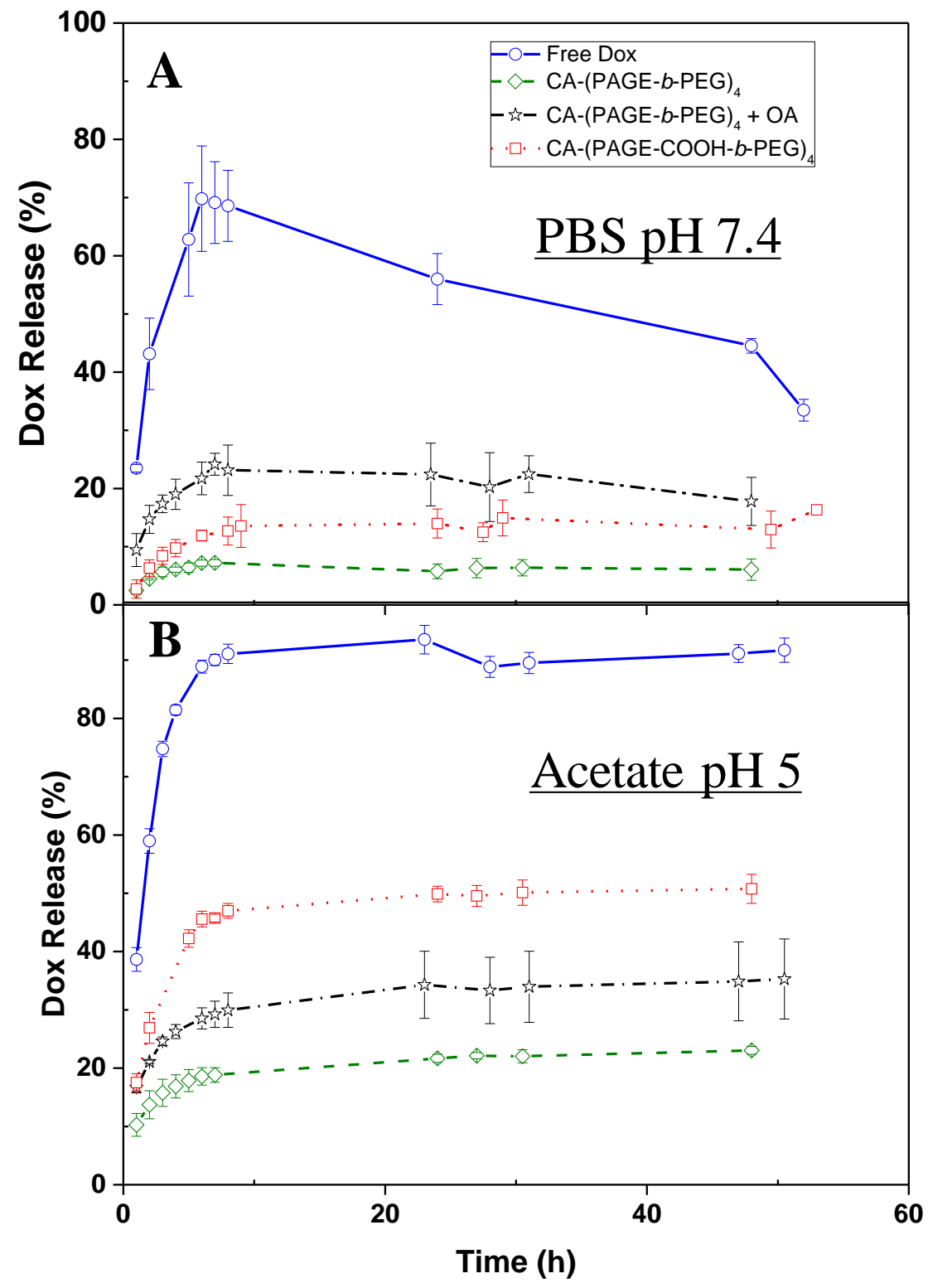

Figure 4. Cumulative release of Doxorubicin from formulations at $37{ }^{\circ} \mathrm{C}$ (A) in PBS buffer at pH 7.4 and (B) in acetate buffer at pH 5. Results show pH-responsiveness for the CA-(PAGE$\mathrm{COOH}-b-\mathrm{PEG})_{4}$ formulation but not for the other two formulations.

\section{In vitro cytotoxicity}


The toxicity of the blank formulations was tested in HeLa cells and the results are presented in Figure S6. All the formulations are non-toxic up to $0.17 \mathrm{mg} / \mathrm{mL}$ with over $80 \%$ cell viability; consistent with the previous reports on bile acid micelles. ${ }^{44}$ To determine the efficiency of the new bile acid-based drug delivery system, the $\mathrm{IC}_{50}$ of the different formulations were obtained on HeLa cells and compared with that of free Dox. The $\mathrm{IC}_{50}$ of free Dox is $2.2 \mu \mathrm{M}$, in agreement with values reported in the literature. ${ }^{22,57}$ The CA-(PAGE- $b$-PEG) $)_{4}$ formulation has an $\mathrm{IC}_{50}$ of 13 $\mu \mathrm{M}$ which is ca. 6 times higher than that of free Dox. For the CA-(PAGE- $b-\mathrm{PEG})_{4}$ with OA formulation, no $\mathrm{IC}_{50}$ was observed at the concentrations tested. Finally, for the CA-(PAGE$\mathrm{COOH}-b$-PEG) $)_{4}$ formulation, the $\mathrm{IC}_{50}$ obtained is $11.4 \mu \mathrm{M}$, comparable to that of the CA$(\mathrm{PAGE}-b-\mathrm{PEG})_{4}$ formulation.

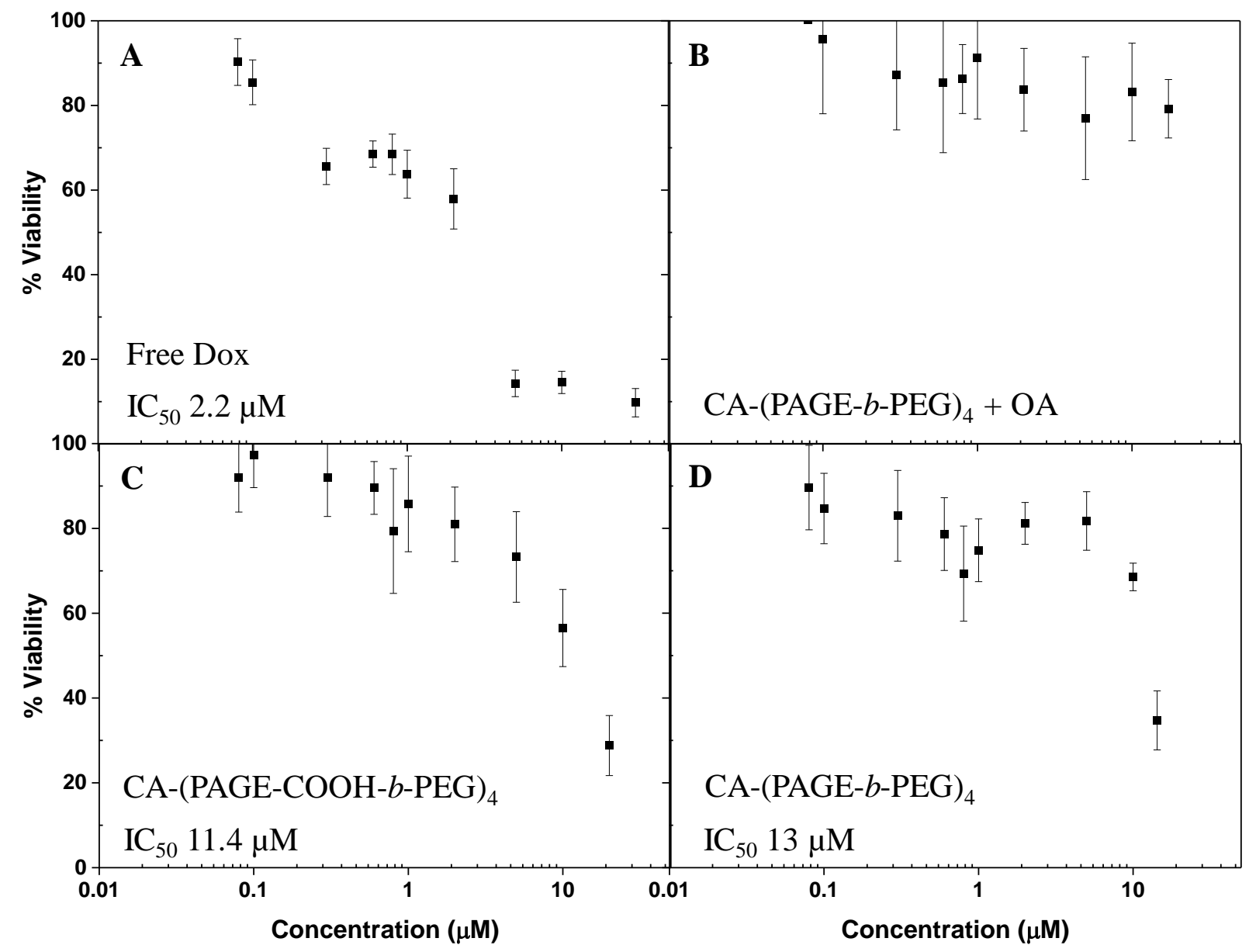

Figure 5. In vitro cytotoxicity obtained on HeLa cells after $48 \mathrm{~h}$ incubation of (A) free Dox compared with the three blank formulations: (B) CA-(PAGE-b-PEG) $)_{4}$ with OA, (C) CA-(PAGE$\mathrm{COOH}-b-\mathrm{PEG})_{4}$, and (D) CA-(PAGE- $\left.b-\mathrm{PEG}\right)_{4}$. The results are presented as mean \pm S.D. 
To clarify these results, cellular entry for the formulation was studied and compared with that of free Dox using flow cytometry (Figure 6). Free Dox is readily internalized inside the cell, but Dox in aggregates of both CA-(PAGE- $b$-PEG) $)_{4}$ and CA-(PAGE-COOH- $b$-PEG $)_{4}$ is less readily internalized. Although previous reports indicate the advantage of spherical over vesicular-shaped nanoparticles for cellular entry, the negative charge of the nanoparticles had a greater impact. ${ }^{58,}$ 59 Presumably, the negative charge of CA-(PAGE-COOH- $b$-PEG) $)_{4}$ may interact with extracellular proteins to facilitate membrane interaction and internalization, and consequently slightly lower the $\mathrm{IC}_{50} .{ }^{59}$ The higher $\mathrm{IC}_{50}$ observed may be a result of cellular entry. Therefore, the $\mathrm{pH}$ responsiveness of the CA-(PAGE-COOH- $b-\mathrm{PEG})_{4}$ formulation does not bring an advantage over the neutral, non-responsive system. The $\mathrm{pH}$-responsiveness was unfavorable due to kinetics of Dox release; Dox release was not sufficiently rapid to promote endosomal escape and cellular uptake was the determining factor for lowering of the $\mathrm{IC}_{50}$. Surprisingly, the formulation with OA showed even less cellular entry than the other two formulations. The presence of $\mathrm{OA}$ affected the cellular entry hence increasing further the $\mathrm{IC}_{50}$, probably due to its impact on the structure of the micelles or the surface properties. The TEM images shows that the micelles prepared from OA are much smaller than those of the other two formulations, but are also dense and irregular in shape. Reports demonstrated the advantage of smaller nanoparticles for cellular entry, but also the effect of particle shape on cellular entry. ${ }^{58,59}$ It is believed that the irregular shape of the Dox-loaded nanoparticles caused by the presence of the OA reduced the cellular internalization process observed via FACS. The proposed drug delivery systems achieve a higher stability avoiding unspecific uptake of Dox, but further studies are necessary to improve the specific nanoparticle internalization in cancer cells and optimize the $\mathrm{pH}$-responsiveness to enable adequate endosomal escape. 

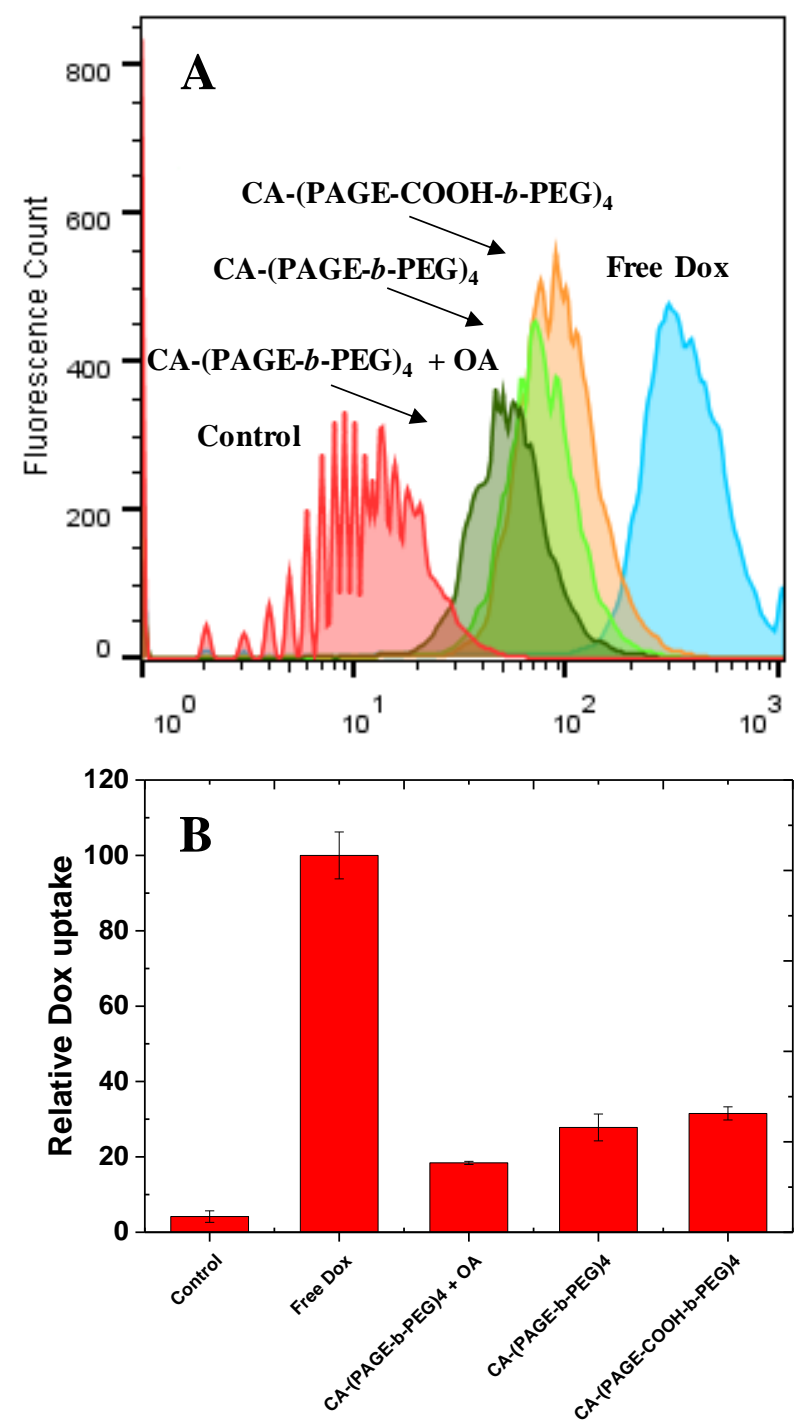

Figure 6. Flow cytometry uptake profiles for formulations of free Dox and with CA-(PAGE- $b$ $\mathrm{PEG})_{4}$, CA-(PAGE- $b$-PEG) $)_{4}$ with OA, and CA-(PAGE-COOH- $b$-PEG) $)_{4}$. Experiment was performed in triplicates with HeLa cells with $2 \mathrm{~h}$ incubation; non-treated HeLa cells were used as control.

\section{CONCLUSION}

Cholic acid-based micelles formed stable micellar aggregates with high Dox loading. Electrostatic interactions in the case of the CA-(PAGE-COOH- $b$-PEG) $)_{4}$ formulation led to higher loading than the CA-(PAGE- $b-\mathrm{PEG})_{4}$ formulation based on hydrophobic interaction. The loading of Dox via electrostatic interactions confers $\mathrm{pH}$-responsiveness to the drug delivery 
system, lowering the $\mathrm{pH}$ from 7.4 to 5 led to an increase in Dox release from 12 to $50 \%$. Moreover, the new nanoparticles are non-toxic with over $80 \%$ cell viability at concentrations up to $0.17 \mathrm{mg} / \mathrm{mL}$. IC $\mathrm{IC}_{50}$ values for both CA-(PAGE- $\left.b-\mathrm{PEG}\right)_{4}$ and CA-(PAGE-COOH- $\left.b-\mathrm{PEG}\right)_{4}$ formulations are higher than that for free Dox and this has been linked to lower cellular internalization of the Dox-loaded micellar aggregates. The CA-(PAGE- $b-\mathrm{PEG})_{4}$ formulation with OA did not show an $\mathrm{IC}_{50}$ at the measured concentration range and had lower cellular internalization than the other two formulations. Cholic acid-based drug delivery systems present advantages of higher Dox loading and $\mathrm{pH}$-responsiveness in release. Challenges related to cellular entry need to be further addressed to achieve an overall successful drug delivery platform. To achieve higher cellular internalization and increased efficiency, the addition of targeting ligand on the surface of the nanoparticle is currently being tested. Further studies are underway to determine the efficiency of the new bile acid-based drug delivery system on drug resistant cancer cell lines and cytotoxic drugs with poor cellular entry.

\section{ACKNOWLEDGMENTS}

Financial support from NSERC of Canada is gratefully acknowledged. AC and XXZ are members of CSACS funded by FRQNT and GRSTB funded by FRSQ. AC thanks the Camille Sandorfy, Charron Lam, and GRSTB Ph.D. scholarships. The authors thank Mrs. Mouna RabebDerbali and Dr. Wilms E. Baille for their technical support.

\section{ASSOCIATED CONTENT}

Supporting information including the following figures is available. SEC traces and ${ }^{1} \mathrm{H}-\mathrm{NMR}$ spectra of block copolymers, critical micellar concentration, Dox calibration curves and in vitro cytotoxicity of formulations.

\section{REFERENCES}

1. Global Burden of Disease Cancer, C. Global, regional, and national cancer incidence, mortality, years of life lost, years lived with disability, and disability-adjusted life-years for 32 cancer groups, 1990 to 2015: A systematic analysis for the global burden of disease study. JAMA Oncology 2017, 3, (4), 524-548.

2. Gonzalez-Angulo, A. M.; Morales-Vasquez, F.; Hortobagyi, G. N. Overview of resistance to systemic therapy in patients with breast cancer. Adv Exp Med Biol 2007, 608, 1-22. 3. Cabral, H.; Kataoka, K. Progress of drug-loaded polymeric micelles into clinical studies. J Control Release 2014, 190, 465-476. 
4. Gong, J.; Chen, M.; Zheng, Y.; Wang, S.; Wang, Y. Polymeric micelles drug delivery system in oncology. J Control Release 2012, 159, (3), 312-323.

5. $\quad$ Chan, J. M.; Valencia, P. M.; Zhang, L.; Langer, R.; Farokhzad, O. C., Polymeric Nanoparticles for Drug Delivery. In Cancer Nanotechnology: Methods and Protocols, Grobmyer, S. R.; Moudgil, B. M., Eds. Humana Press: Totowa, NJ, 2010; pp 163-175.

6. Kataoka, K.; Harada, A.; Nagasaki, Y. Block copolymer micelles for drug delivery: design, characterization and biological significance. Adv Drug Deliver Rev 2001, 47, (1), 113 131.

7. Kim, D. W.; Kim, S. Y.; Kim, H. K.; Kim, S. W.; Shin, S. W.; Kim, J. S.; Park, K.; Lee, M. Y.; Heo, D. S. Multicenter phase II trial of Genexol-PM, a novel Cremophor-free, polymeric micelle formulation of paclitaxel, with cisplatin in patients with advanced non-small-cell lung cancer. Ann of Oncol 2007, 18, (12), 2009-2014.

8. Lee, K. S.; Chung, H. C.; Im, S. A.; Park, Y. H.; Kim, C. S.; Kim, S.-B.; Rha, S. Y.; Lee, M. Y.; Ro, J. Multicenter phase II trial of Genexol-PM, a Cremophor-free, polymeric micelle formulation of paclitaxel, in patients with metastatic breast cancer. Breast Cancer Res Tr 2008, $108,(2), 241-250$.

9. $\quad$ Hamaguchi, T.; Matsumura, Y.; Suzuki, M.; Shimizu, K.; Goda, R.; Nakamura, I.; Nakatomi, I.; Yokoyama, M.; Kataoka, K.; Kakizoe, T. NK105, a paclitaxel-incorporating micellar nanoparticle formulation, can extend in vivo antitumour activity and reduce the neurotoxicity of paclitaxel. Br J Cancer 2005, 92, (7), 1240-1246.

10. Alexander, S.; Cosgrove, T.; Prescott, S. W.; Castle, T. C. Flurbiprofen Encapsulation Using Pluronic Triblock Copolymers. Langmuir 2011, 27, (13), 8054-8060.

11. Varshosaz, J.; Hasanzadeh, F.; Eslamdoost, M. Optimization of self-assembling properties of fatty acids grafted to methoxy poly(ethylene glycol) as nanocarriers for etoposide. Acta Pharm 2012, 62, (1), 31-44.

12. Wang, X.; Wu, G.; Lu, C.; Zhao, W.; Wang, Y.; Fan, Y.; Gao, H.; Ma, J. A novel delivery system of doxorubicin with high load and $\mathrm{pH}$-responsive release from the nanoparticles of poly ( $\alpha, \beta$-aspartic acid) derivative. Eur J Pharm Sci 2012, 47, (1), 256-264.

13. Shen, Y.; Jin, E.; Zhang, B.; Murphy, C. J.; Sui, M.; Zhao, J.; Wang, J.; Tang, J.; Fan, M.; Van Kirk, E.; Murdoch, W. J. Prodrugs Forming High Drug Loading Multifunctional Nanocapsules for Intracellular Cancer Drug Delivery. JACS 2010, 132, (12), 4259-4265.

14. Zhang, Y.; Ren, T.; Gou, J.; Zhang, L.; Tao, X.; Tian, B.; Tian, P.; Yu, D.; Song, J.; Liu, X.; Chao, Y.; Xiao, W.; Tang, X. Strategies for improving the payload of small molecular drugs in polymeric micelles. $J$ Control Release 2017, 261, 352-366.

15. Ke, X.; Ng, V. W. L.; Ono, R. J.; Chan, J. M. W.; Krishnamurthy, S.; Wang, Y.; Hedrick, J. L.; Yang, Y. Y. Role of non-covalent and covalent interactions in cargo loading capacity and stability of polymeric micelles. J Control Release 2014, 193, 9-26.

16. Gadelle, F.; Koros, W. J.; Schechter, R. S. Solubilization of Aromatic Solutes in Block Copolymers. Macromolecules 1995, 28, (14), 4883-4892.

17. Soliman, G. M.; Sharma, R.; Choi, A. O.; Varshney, S. K.; Winnik, F. M.; Kakkar, A. K.; Maysinger, D. Tailoring the efficacy of nimodipine drug delivery using nanocarriers based on A2B miktoarm star polymers. Biomaterials 2010, 31, (32), 8382-92.

18. Letchford, K.; Liggins, R.; Burt, H. Solubilization of hydrophobic drugs by methoxy poly(ethylene glycol)-block-polycaprolactone diblock copolymer micelles: theoretical and experimental data and correlations. J Pharm Sci 2008, 97, (3), 1179-90. 
19. Sharma, A.; Soliman, G. M.; Al-Hajaj, N.; Sharma, R.; Maysinger, D.; Kakkar, A. Design and Evaluation of Multifunctional Nanocarriers for Selective Delivery of Coenzyme Q10 to Mitochondria. Biomacromolecules 2012, 13, (1), 239-252.

20. Yan, J.; Ye, Z.; Chen, M.; Liu, Z.; Xiao, Y.; Zhang, Y.; Zhou, Y.; Tan, W.; Lang, M. Fine Tuning Micellar Core-Forming Block of Poly(ethylene glycol)-block-poly( $\varepsilon$-caprolactone) Amphiphilic Copolymers Based on Chemical Modification for the Solubilization and Delivery of Doxorubicin. Biomacromolecules 2011, 12, (7), 2562-2572.

21. LeDevedec, F.; Houdaihed, L.; Allen, C. Anionic polymerization of an amphiphilic copolymer for preparation of block copolymer micelles stabilized by $\pi-\pi$ stacking interactions. $J$ Vis Exp 2016, 116, e54422.

22. Chen, W.; Meng, F.; Cheng, R.; Deng, C.; Feijen, J.; Zhong, Z. Facile construction of dual-bioresponsive biodegradable micelles with superior extracellular stability and activated intracellular drug release. J Control Release 2015, 210, 125-133.

23. Shuai, X.; Merdan, T.; Schaper, A. K.; Xi, F.; Kissel, T. Core-Cross-Linked Polymeric Micelles as Paclitaxel Carriers. Bioconjugate Chem 2004, 15, (3), 441-448.

24. Wu, Y.; Chen, W.; Meng, F.; Wang, Z.; Cheng, R.; Deng, C.; Liu, H.; Zhong, Z. Corecrosslinked $\mathrm{pH}$-sensitive degradable micelles: A promising approach to resolve the extracellular stability versus intracellular drug release dilemma. J Control Release 2012, 164, (3), 338-345.

25. Lin, W.; Kim, D. pH-Sensitive Micelles with Cross-Linked Cores Formed from Polyaspartamide Derivatives for Drug Delivery. Langmuir 2011, 27, (19), 12090-12097.

26. Zhong, Y.; Goltsche, K.; Cheng, L.; Xie, F.; Meng, F.; Deng, C.; Zhong, Z.; Haag, R. Hyaluronic acid-shelled acid-activatable paclitaxel prodrug micelles effectively target and treat CD44-overexpressing human breast tumor xenografts in vivo. Biomaterials 2016, 84, 250-61. 27. Yin, S.; Huai, J.; Chen, X.; Yang, Y.; Zhang, X.; Gan, Y.; Wang, G.; Gu, X.; Li, J. Intracellular delivery and antitumor effects of a redox-responsive polymeric paclitaxel conjugate based on hyaluronic acid. Acta Biomater 2015, 26, 274-85.

28. Xu, R.; Fisher, M.; Juliano, R. L. Targeted albumin-based nanoparticles for delivery of amphipathic drugs. Bioconjug Chem 2011, 22, (5), 870-8.

29. Prabaharan, M.; Grailer, J. J.; Pilla, S.; Steeber, D. A.; Gong, S. Amphiphilic multi-armblock copolymer conjugated with doxorubicin via $\mathrm{pH}$-sensitive hydrazone bond for tumortargeted drug delivery. Biomaterials 2009, 30, (29), 5757-5766.

30. Lv, S.; Song, W.; Tang, Z.; Li, M.; Yu, H.; Hong, H.; Chen, X. Charge-Conversional PEG-Polypeptide Polyionic Complex Nanoparticles from Simple Blending of a Pair of Oppositely Charged Block Copolymers as an Intelligent Vehicle for Efficient Antitumor Drug Delivery. Mol Pharm 2014, 11, (5), 1562-1574.

31. Wang, C. H.; Wang, W. T.; Hsiue, G. H. Development of polyion complex micelles for encapsulating and delivering amphotericin B. Biomaterials 2009, 30, (19), 3352-8.

32. Eckman, A. M.; Tsakalozou, E.; Kang, N. Y.; Ponta, A.; Bae, Y. Drug release patterns and cytotoxicity of PEG-poly(aspartate) block copolymer micelles in cancer cells. Pharm Res 2012, 29, (7), 1755-67.

33. Xu, H.; Yang, D.; Cai, C.; Gou, J.; Zhang, Y.; Wang, L.; Zhong, H.; Tang, X. Dualresponsive mPEG-PLGA-PGlu hybrid-core nanoparticles with a high drug loading to reverse the multidrug resistance of breast cancer: an in vitro and in vivo evaluation. Acta Biomater 2015, 16, 156-68.

34. Xu, H.; Cai, C.; Gou, J.; Sui, B.; Jin, J.; Xu, H.; Zhang, Y.; Wang, L.; Zhai, Y.; Tang, X. Self-Assembled Monomethoxy (Polyethylene Glycol)-b-P(D,L-Lactic-co-Glycolic Acid)-b-P(L- 
Glutamic Acid) Hybrid-Core Nanoparticles for Intracellular pH-Triggered Release of Doxorubicin. J Biomed Nanotechnol 2015, 11, (8), 1354-69.

35. Yang, C.; Tan, J. P. K.; Cheng, W.; Attia, A. B. E.; Ting, C. T. Y.; Nelson, A.; Hedrick, J. L.; Yang, Y.-Y. Supramolecular nanostructures designed for high cargo loading capacity and kinetic stability. Nano Today 2010, 5, (6), 515-523.

36. Yang, C.; Ebrahim Attia, A. B.; Tan, J. P. K.; Ke, X.; Gao, S.; Hedrick, J. L.; Yang, Y.Y. The role of non-covalent interactions in anticancer drug loading and kinetic stability of polymeric micelles. Biomaterials 2012, 33, (10), 2971-2979.

37. Su, W.; Luo, X.-h.; Wang, H.-f.; Li, L.; Feng, J.; Zhang, X.-Z.; Zhuo, R.-X. Hyperbranched Polycarbonate-Based Multimolecular Micelle with Enhanced Stability and Loading Efficiency. Macromol Rapid Comm 2011, 32, (4), 390-396.

38. Kim, S. H.; Tan, J. P. K.; Nederberg, F.; Fukushima, K.; Colson, J.; Yang, C.; Nelson, A.; Yang, Y.-Y.; Hedrick, J. L. Hydrogen bonding-enhanced micelle assemblies for drug delivery. Biomaterials 2010, 31, (31), 8063-8071.

39. Tsoi, K. M.; MacParland, S. A.; Ma, X.-Z.; Spetzler, V. N.; Echeverri, J.; Ouyang, B.; Fadel, S. M.; Sykes, E. A.; Goldaracena, N.; Kaths, J. M.; Conneely, J. B.; Alman, B. A.; Selzner, M.; Ostrowski, M. A.; Adeyi, O. A.; Zilman, A.; McGilvray, I. D.; Chan, W. C. W. Mechanism of hard-nanomaterial clearance by the liver. Nat Mater 2016, 15, (11), 1212-1221.

40. Le Dévédec, F.; Fuentealba, D.; Strandman, S.; Bohne, C.; Zhu, X. X. Aggregation Behavior of Pegylated Bile Acid Derivatives. Langmuir 2012, 28, (37), 13431-13440.

41. Le Devedec, F.; Strandman, S.; Baille, W. E.; Zhu, X. X. Functional Star Block Copolymers with a Cholane Core: Thermo-Responsiveness and Aggregation Behavior. Polymer 2013, 54, 3898-3903.

42. Shao, Y.; Jia, Y.-G.; Shi, C.; Luo, J.; Zhu, X. X. Block and Random Copolymers Bearing Cholic Acid and Oligo(ethylene glycol) Pendant Groups: Aggregation, Thermosensitivity, and Drug Loading. Biomacromolecules 2014, 15, (5), 1837-1844.

43. Despa, F.; Luo, J. T.; Li, J.; Duan, Y.; Lam, K. S. Cholic acid micelles-controlling the size of the aqueous cavity by PEGylation. Phys Chem Chem Phys 2010, 12, (7), 1589-1594.

44. Le Dévédec, F.; Strandman, S.; Hildgen, P.; Leclair, G.; Zhu, X. X. Pegylated bile acids for use in drug delivery systems enhanced solubility and bioavailability of itraconazole. . Mol Pharm 2013, 10, 3057-3066.

45. Juo, J.; Giguère, G.; Zhu, X. X. Asymmetric Poly(ethylene glycol) Star Polymers with a Cholic Acid Core and Their Aggregation Properties. Biomacromolecules 2009, 10, 900-906.

46. Gouin, S.; Zhu, X. X. Synthesis of 3 alpha- and 3 beta-dimers from selected bile acids. Steroids 1996, 61, (11), 664-9.

47. Zhang, X.; Sun, X.; Li, J.; Zhang, X.; Gong, T.; Zhang, Z. Lipid nanoemulsions loaded with doxorubicin-oleic acid ionic complex: characterization, in vitro and in vivo studies. Die Pharmazie 2011, 66, (7), 496-505.

48. Topel, Ö.; Çakır, B. A.; Budama, L.; Hoda, N. Determination of critical micelle concentration of polybutadiene-block-poly(ethyleneoxide) diblock copolymer by fluorescence spectroscopy and dynamic light scattering. J Mol Liq 2013, 177, 40-43.

49. Allen, C.; Maysinger, D.; Eisenberg, A. Nano-engineering block copolymer aggregates for drug delivery. Colloid Surface B 1999, 16, (1), 3-27.

50. Shao, Y.; Shi, C.; Xu, G.; Guo, D.; Luo, J. Photo and redox dual responsive reversibly cross-linked nanocarrier for efficient tumor-targeted drug delivery. ACS Appl Mater Interfaces 2014, 6, (13), 10381-92. 
51. Li, Y.; Xiao, K.; Luo, J.; Xiao, W.; Lee, J. S.; Gonik, A. M.; Kato, J.; Dong, T. A.; Lam, K. S. Well-defined, reversible disulfide cross-linked micelles for on-demand paclitaxel delivery. Biomaterials 2011, 32, (27), 6633-45.

52. Janssen, M. J. H.; Crommelin, D. J. A.; Storm, G.; Hulshoff, A. Doxorubicin decomposition on storage. Effect of $\mathrm{pH}$, type of buffer and liposome encapsulation. Int J Pharm 1985, 23, (1), 1-11.

53. Wu, D. C.; Ofner, C. M. Adsorption and Degradation of Doxorubicin from Aqueous Solution in Polypropylene Containers. AAPS PharmSciTech 2013, 14, (1), 74-77.

54. Zutshi, A. Physicochemical characterization and stability of doxorubicin in aqueous solutions. University of Florida, Fl, 1994.

55. Fritze, A.; Hens, F.; Kimpfler, A.; Schubert, R.; Peschka-Süss, R. Remote loading of doxorubicin into liposomes driven by a transmembrane phosphate gradient. BBA-Biomembranes 2006, 1758, (10), 1633-1640.

56. Thorat, N. D.; Bohara, R. A.; Noor, M. R.; Dhamecha, D.; Soulimane, T.; Tofail, S. A. M. Effective Cancer Theranostics with Polymer Encapsulated Superparamagnetic Nanoparticles: Combined Effects of Magnetic Hyperthermia and Controlled Drug Release. ACS Biomater Sci Eng 2017, 3, (7), 1332-1340.

57. Plourde, K.; Derbali, R. M.; Desrosiers, A.; Dubath, C.; Vallée-Bélisle, A.; Leblond, J. Aptamer-based liposomes improve specific drug loading and release. J Control Release 2017, 251, 82-91.

58. Salatin, S.; Maleki Dizaj, S.; Yari Khosroushahi, A. Effect of the surface modification, size, and shape on cellular uptake of nanoparticles. Cell Biol Int 2015, 39, (8), 881-890.

59. Zhao, J.; Lu, H.; Wong, S.; Lu, M.; Xiao, P.; Stenzel, M. H. Influence of nanoparticle shapes on cellular uptake of paclitaxel loaded nanoparticles in 2D and 3D cancer models. Polym Chem 2017, 8, (21), 3317-3326. 


\section{Bile acid-based drug delivery systems for enhanced}

\section{doxorubicin encapsulation: Comparing hydrophobic}

\section{and ionic interactions in drug loading and release}

Alexander J. Cunningham ${ }^{1}$, Mattieu Robinson ${ }^{3}$, Xavier Banquy ${ }^{2}$, Jeanne Leblond-Chain ${ }^{2}$, and $X . X . Z h u^{1, *}$

${ }^{1}$ Département de Chimie, Université de Montréal, C.P. 6128, Succ. Centre-ville, Montréal, QC, H3C 3J7, Canada

${ }^{2}$ Faculté de Pharmacie, Université de Montréal, C.P. 6128, Succ. Centre-ville, Montréal, QC, H3C 3J7, Canada

${ }^{3}$ Département de Gérontologie, Université de Sherbrooke, Sherbrooke, QC, J1H 4C4, Canada

* Correspondence to: julian.zhu@umontreal.ca

\section{Critical micellization concentration (CMC) determination}

The CMC was determined according to a previously published protocol. ${ }^{48}$ Briefly, pyrene was dissolved in methanol to give a final concentration of $10^{-6} \mathrm{M}$ in $5 \mathrm{~mL} \mathrm{PBS}$, followed by the evaporation of methanol. A stock solution at $8 \mathrm{mg} / \mathrm{mL}$ of copolymer micelles was prepared via a nanoprecipitation method. This stock solution was diluted with buffer to obtain a series of 
solutions with copolymer concentrations ranging from $10^{-4}$ to $8 \mathrm{mg} / \mathrm{mL}$ and added to the vials containing pyrene. The solutions were stirred for $48 \mathrm{~h}$ to allow the pyrene to equilibrate. Fluorescence spectra were recorded on a Cary Eclipse fluorescence spectrometer (Agilent). The emission wavelength was set to $335 \mathrm{~nm}$ with a slit width of 2.5 for both excitation and emission. The $I_{3} / I_{1}$ ratio was obtained from the ratio of fluorescence intensity at $383 \mathrm{~nm}\left(\mathrm{I}_{3}\right)$ and $373 \mathrm{~nm}$ $\left(\mathrm{I}_{1}\right)$.

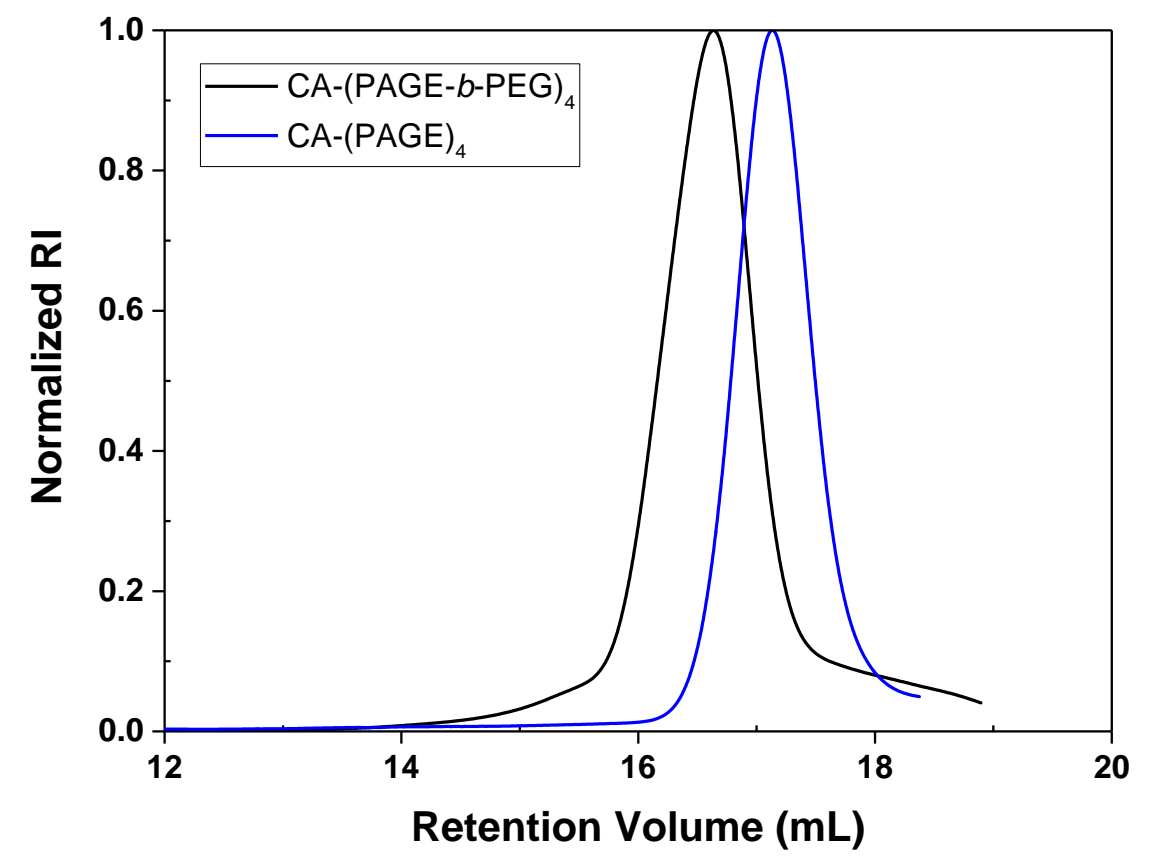

Figure S1. SEC traces of homopolymer CA-(PAGE) ${ }_{4}$ and block copolymer CA-(PAGE- $b$ PEG) $)_{4}$ THF was used as eluent with a flow rate of $1 \mathrm{~mL} / \mathrm{min}$ at $35^{\circ} \mathrm{C}$ and analyzed with a calibration curve based on PS standards. Figure shows increase in molecular weight following polymerization of PEG and narrow dispersity. 


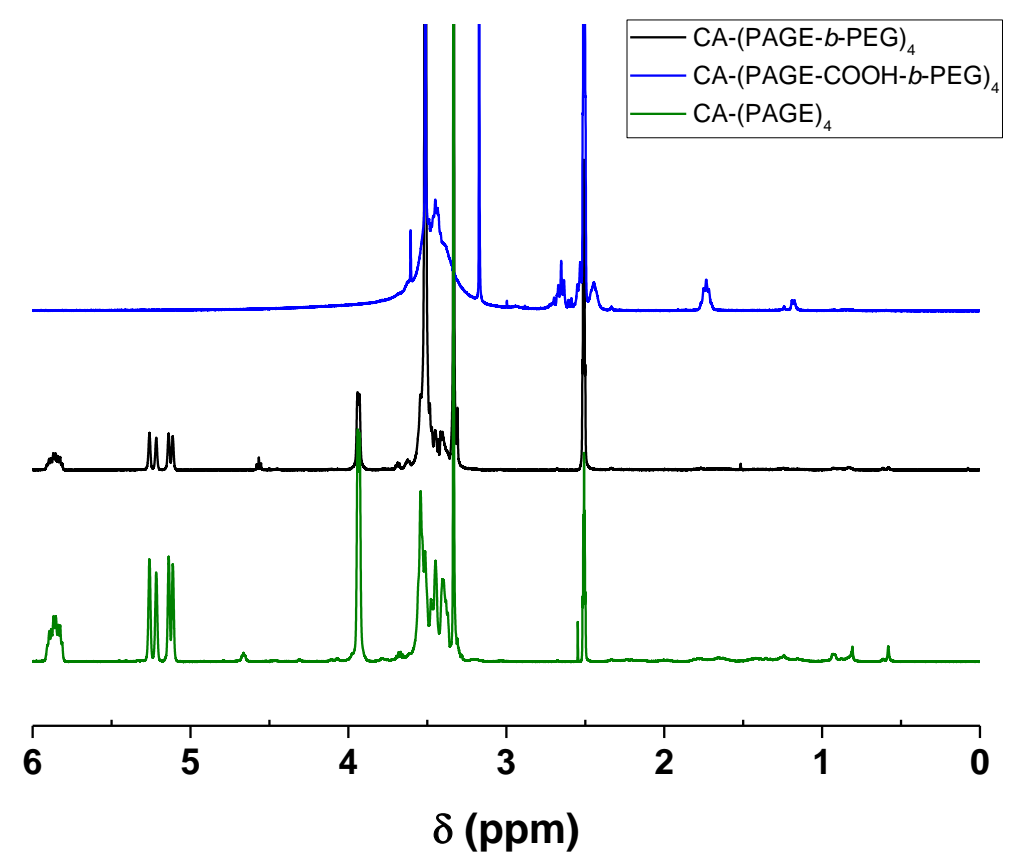

Figure S2. ${ }^{1} \mathrm{H}$ NMR spectra of homopolymer CA-(PAGE) 4 , and block copolymers CA-(PAGE$b$-PEG $)_{4}$ and CA-(PAGE-COOH- $b$-PEG $)_{4}$ in $\mathrm{d}_{6}$-DMSO. The disappearance of the methine and methylene peaks at $5.8-6.0 \mathrm{ppm}$ and $5.1-5.3 \mathrm{ppm}$ of pendant allyl group on PAGE backbone testifies to the successful functionalization.

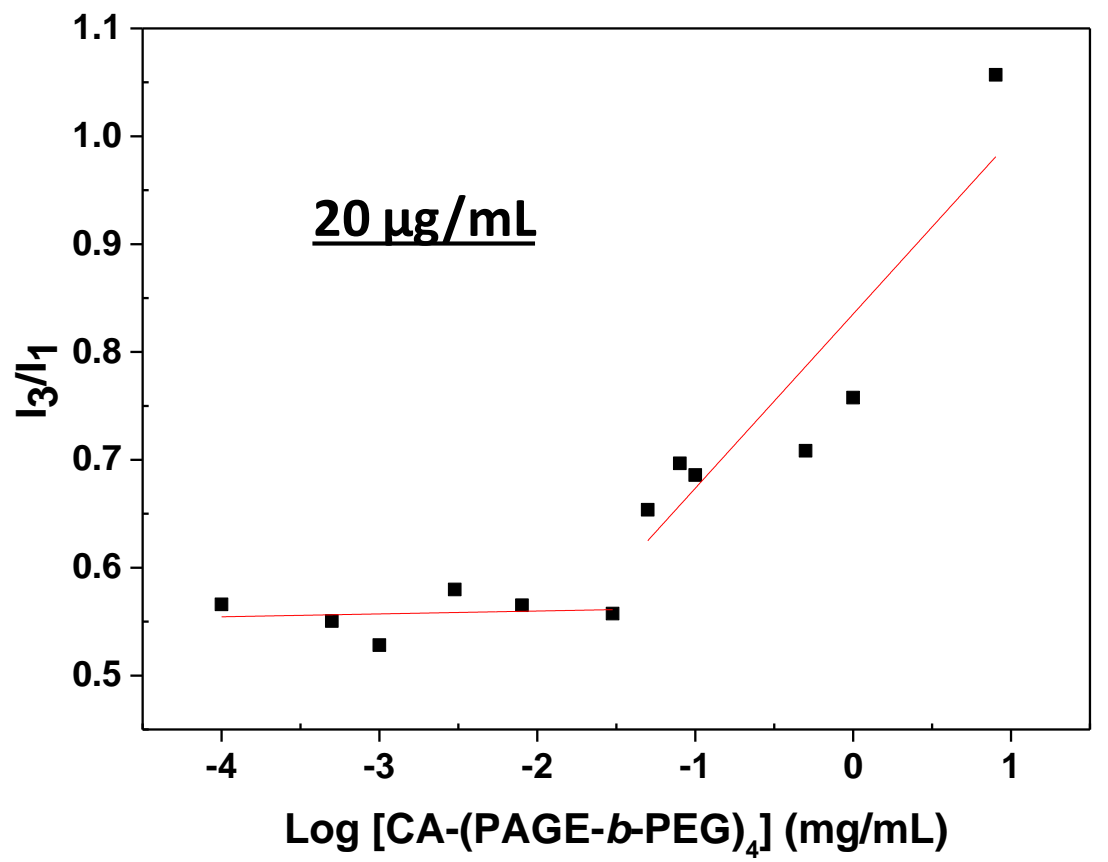


Figure S3. Critical micellar concentration measured by fluorescence spectroscopy using pyrene as a probe. The ratio $I_{3} / I_{1}$ (obtained from fluorescence spectra) is plotted as a function of CA(PAGE- $b-\mathrm{PEG})_{4}$ concentration. $\mathrm{CMC}$ is obtained by the intercept of the two linear regressions. In this case, $\mathrm{CMC}=20 \mu \mathrm{g} / \mathrm{mL}$.
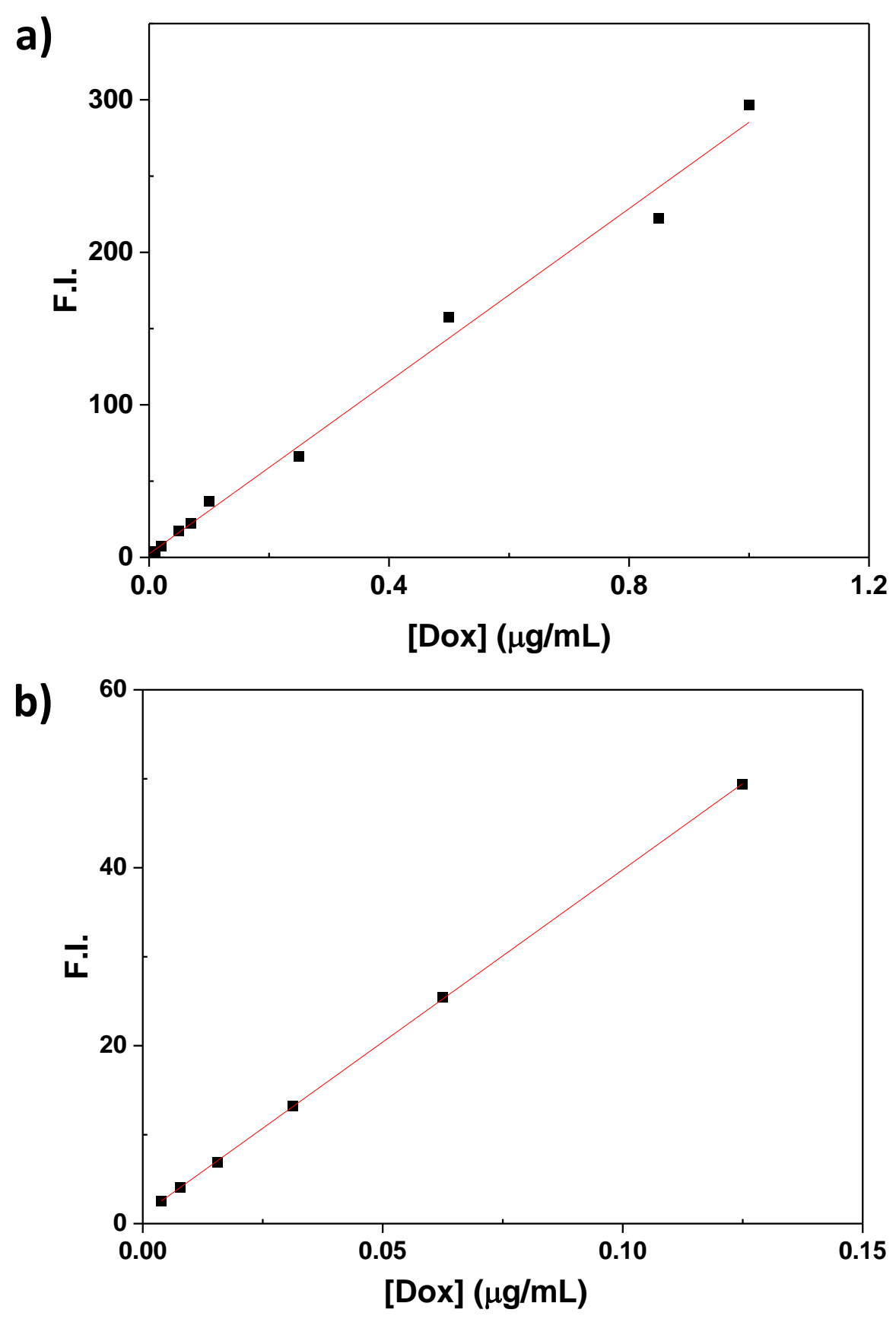
Figure S4. Dox calibration curves for release experiment. Dox was quantified in outer water for the release experiment by taking $1 \mathrm{~mL}$ of outer water, measuring fluorescence intensity, and quantifying the corresponding Dox amount using this calibration curve. Calibration curve was obtained by measuring fluorescence intensity of Dox in (a) 1/1 DMSO/PBS (pH 7.4) solution and (b) 1/1 DMSO/Acetate (pH5) solution.

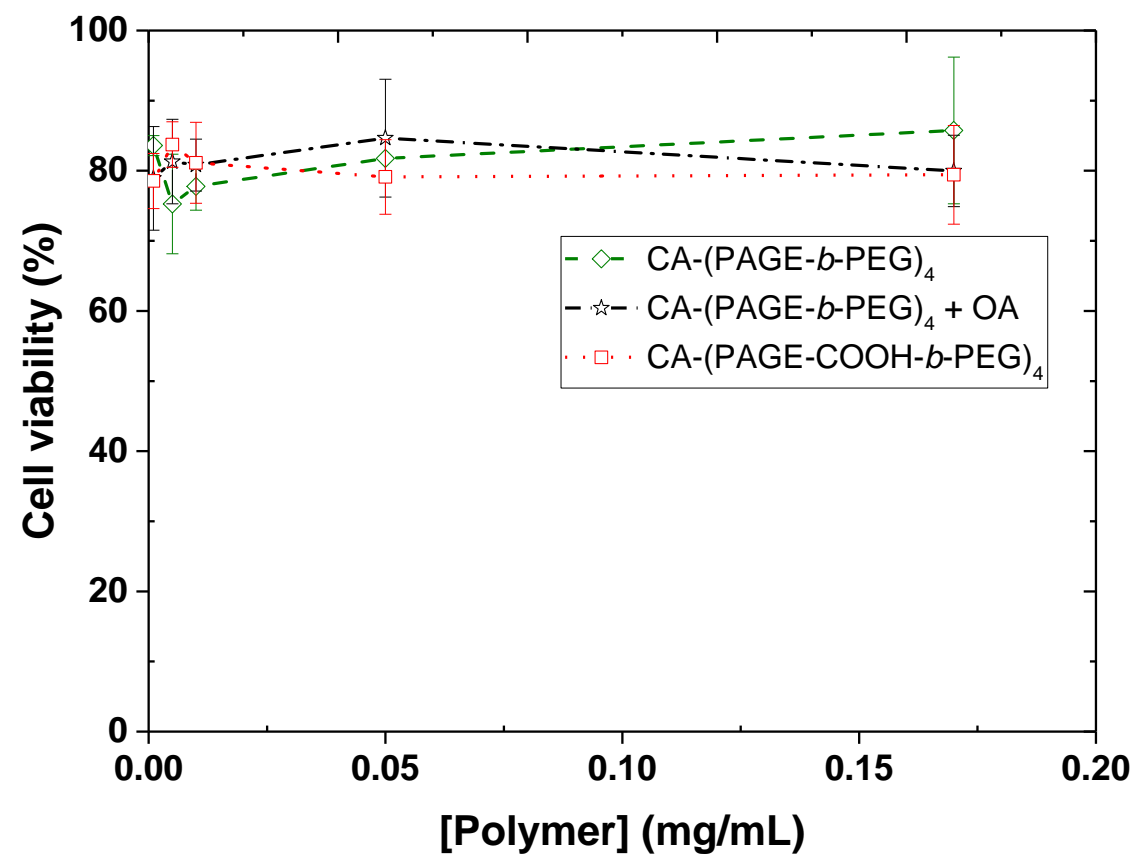

Figure S6. In vitro cytotoxicity of blank formulations was tested in HeLa cells using the MTT assay with a $48 \mathrm{~h}$ incubation. The results are expressed as mean \pm S.D. Results show the formulations are non-toxic up to $0.17 \mathrm{mg} / \mathrm{mL}$. 